\title{
Flash Flood Forecasting: An Ingredients-Based Methodology
}

\author{
Charles A. Doswell III, Harold E. Brooks, and Robert A. Maddox \\ NOAA/Environmental Research Laboratories, National Severe Storms Laboratory, Norman, Oklahoma
}

(Manuscript received 31 August 1995, in final form 5 June 1996)

\begin{abstract}
An approach to forecasting the potential for flash flood-producing storms is developed, using the notion of basic ingredients. Heavy precipitation is the result of sustained high rainfall rates. In turn, high rainfall rates involve the rapid ascent of air containing substantial water vapor and also depend on the precipitation efficiency. The duration of an event is associated with its speed of movement and the size of the system causing the event along the direction of system movement.

This leads naturally to a consideration of the meteorological processes by which these basic ingredients are brought together. A description of those processes and of the types of heavy precipitation-producing storms suggests some of the variety of ways in which heavy precipitation occurs. Since the right mixture of these ingredients can be found in a wide variety of synoptic and mesoscale situations, it is necessary to know which of the ingredients is critical in any given case. By knowing which of the ingredients is most important in any given case, forecasters can concentrate on recognition of the developing heavy precipitation potential as meteorological processes operate. This also helps with the recognition of heavy rain events as they occur, a challenging problem if the potential for such events has not been anticipated.

Three brief case examples are presented to illustrate the procedure as it might be applied in operations. The cases are geographically diverse and even illustrate how a nonconvective heavy precipitation event fits within this methodology. The concept of ingredients-based forecasting is discussed as it might apply to a broader spectrum of forecast events than just flash flood forecasting.
\end{abstract}

\section{Introduction}

Flash flooding has become the convective stormrelated event annually producing the most fatalities. Whereas the system for reducing casualties from tornadoes, including not only forecasts and warnings but also public preparedness, has improved steadily since the 1950s and continues to improve, the comparable system for flash floods has experienced less progress. A major challenge associated with flash flooding is the quantitative character of the forecast: the task is not just to forecast the occurrence of an event, which is difficult enough by itself, but to anticipate the magnitude of the event. It is the amount of the precipitation that transforms an otherwise ordinary rainfall into an extraordinary, life-threatening situation. This challenge is exacerbated by the interaction of the meteorology with hydrology. A given rainfall event's chances to produce a flash flood are dramatically affected by such factors as antecedent precipitation, the size of the drainage basin, the topography of the basin, the amount of urban

Corresponding author address: Dr. Charles A. Doswell III, National Severe Storms Laboratory, 1313 Halley Circle, Norman, OK 73069.

E-mail: doswell@nssl.uoknor.edu use within the basin, and so on. Thus, a flash flood event is the concatenation of a meteorological event with a particular hydrological situation. We are not prepared to treat the hydrological aspects of the flash flood problem in this paper, but we are by no means implying their lack of relevance.

As noted by Spiegler (1970), albeit in a different context, quantitative precipitation forecasting (QPF) is a "formidable challenge." Rainfall, per se, is a quite ordinary event, which is why it can be difficult to rouse public concern when rainfall becomes life threatening. The public has no difficulty becoming concerned about the threat associated with extraordinary weather events such as tornadoes, but rain is both common and benign in the vast majority of circumstances. The fact that QPF is difficult to do [see Mostek and Junker (1989) and Olson et al. (1995) for some QPF verification results ] makes the task that much more challenging; forecast credibility is certainly part of the problem. Even if we could do QPF with perfect skill, rousing the public to recognition of the threat might continue to be a problem.

Many operational studies associated with QPF are local or regional in scope (e.g., Belville and Johnson 1982). Moreover, such studies typically are empirical, in that they are based heavily on statistical associations between candidate precipitation predictors and precip- 
itation (e.g., Charba 1990), without establishing a physical connection between predictor and predictand. We want to provide forecasters with a basic framework for understanding the occurrence of heavy precipitation that is neither limited in geographical application nor based on statistical relationships. Instead, we wish to develop a physical basis for understanding why heavy precipitation occurs that is not region specific and is not prone to obsolescence through advances in science and/or technology. In fact, when the basis is properly constructed, it permits an easy and obvious integration of new scientific concepts. We believe that a QPF scheme using an "ingredients" basis can be improved and refined through advances in scientific understanding and technological tools, but the basis itself should remain essentially unchanged, barring perhaps a true revolution in our understanding (a pervasive "paradigm change"').

Accordingly, in section 2, we develop what we believe to be such an ingredients-oriented basis for predicting heavy precipitation. In section 3, we will provide an overview of the meteorological processes associated with bringing these ingredients together, primarily in midlatitudes. The same ingredients are associated with tropical occurrences of heavy precipitation, but the processes by which they are brought together may be different in important ways. Section 4 then provides three case examples that serve to illustrate the ideas developed in sections 2 and 3, and section 5 offers a summary and discussion.

\section{Ingredients for flash floods}

\section{a. Ingredients for heavy precipitation}

\section{1) A SIMPLE CONCEPT OF HEAVY PRECIPITATION}

There is an almost absurdly simple concept of how heavy precipitation comes about that by its very simplicity makes the issues leading to heavy precipitation quite clear. It takes the form of a simple statement (attributable to C. F. Chappell) of quantitative precipitation forecasting: the heaviest precipitation occurs where the rainfall rate is the highest for the longest time. That is, at any point on the earth, ${ }^{1}$ if $\bar{R}$ is the average rainfall rate and $D$ is the duration of the rainfall, then the total precipitation produced, $P$, is simply

$$
P=\bar{R} D .
$$

Flash flood events arise from high to extremely high rainfall rates, whereas river flood events are associated with rainfall events over days and perhaps months. The infamous northern Mississippi and Missouri River

\footnotetext{
${ }^{1}$ The point of view here is Eulerian and the development that fol lows continues in this perspective.
}

floods of 1993 clearly were due to the persistence of rainfall over many weeks, but there were flash floods with quite high rainfall rates embedded within the summer events of 1993. Flash floods caused many of the deaths during the summer of 1993; flash floods, of course, are the main concern within this paper.

We have not provided quantitative thresholds for what we consider to be "high" or "extremely high" rainfall rates, nor have we done so for "long" or "extremely long" durations. Thresholds can be intellectual traps for the unwary and what constitutes an important threshold in one hydrometeorological situation may be quite unimportant in another, as we shall illustrate below. Broadly speaking, moderately high rainfall rates begin at about $25 \mathrm{~mm}(\sim$ one in. $) \mathrm{h}^{-1}$, and moderately long durations begin at about $1 \mathrm{~h}$, but these should be considered only as the crudest of guidelines.

\section{2) INGREDIENTS FOR HIGH PRECIPITATION RATE}

With this simple "law" in mind, one key issue is to consider how heavy precipitation rates occur: from a synoptic viewpoint, precipitation is produced by lifting moist air to condensation. The instantaneous rainfall rate at a particular point, $R$, is assumed to be proportional to the magnitude of the vertical moisture flux, $w q$, where $w$ is the ascent rate and $q$ is the mixing ratio of the rising air. ${ }^{2}$ This means rising air should have a substantial water vapor content and a rapid ascent rate if a significant precipitation rate is to develop. The vertical moisture flux can be related to the condensation rate, which in turn is the ultimate source for precipitation. Of course, not all the water vapor flowing into a cloud falls out as precipitation. This naturally brings up the subject of precipitation efficiency. The precipitation efficiency, $E$, is the coefficient of proportionality relating rainfall rate to input water flux, so that

$$
R=E w q
$$

Precipitation efficiency is defined as the ratio of the mass of water falling as precipitation, $m_{p}$, to the influx of water vapor mass into the cloud, $m_{i}$, such that $E$ $=m_{p} / m_{i}$. The details of this definition are given in the appendix. Figure 1 illustrates this process schematically to show that precipitation efficiency is most logically understood as a time average over the history of a precipitation-producing weather system. If calculated at any particular instant, precipitation efficiency might be zero (as when no rainfall is occurring early in the life cycle of the system) or it might be infinite (as when

\footnotetext{
${ }^{2}$ Note that the instantaneous flux of water vapor into the thunderstorm is not directly equal to the precipitation rate. Many issues influence the rate at which input water vapor falls out of a thunderstorm. Our simplifying assumption is that the higher the input flux, the greater the precipitation rate.
} 


\section{Precipitation Efficiency}

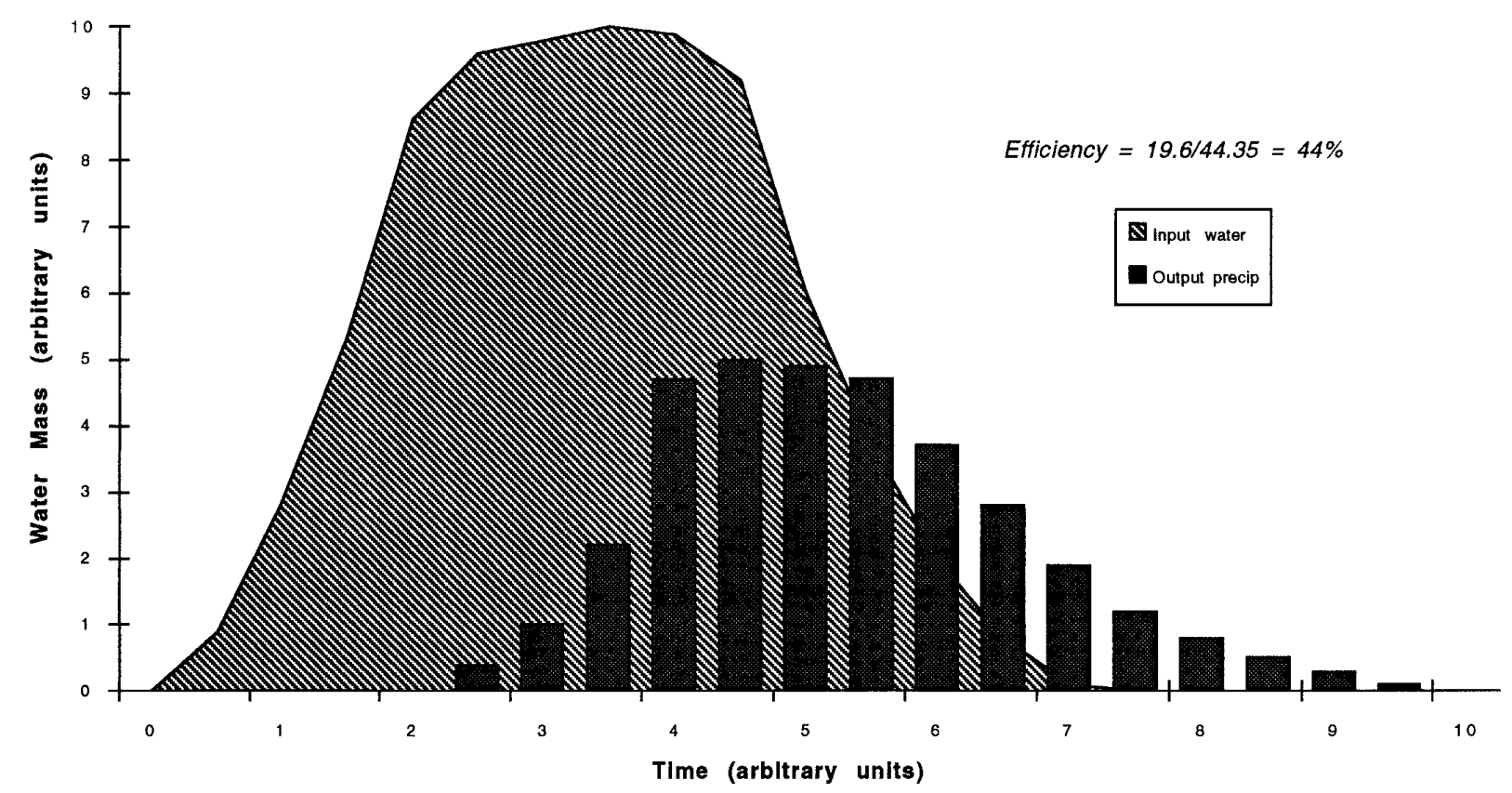

FIG. 1. Schematic illustration of the time variation of water vapor input (cross-hatched area) and the precipitation output (vertical bars) over the lifetime of a precipitation system. The units are arbitrary, so the system being portrayed can be any precipitating process with a developing phase (time $=0-3$ units), a mature phase (time $=3-6$ units), and a dissipating phase (time $=6-10$ units). For this example, the areas under the respective curves give a precipitation efficiency of about $44 \%$.

rain is continuing to fall from a dissipating system in which the water influx has gone to zero). The smallest unit for which it makes sense to calculate precipitation efficiency is a convective cell. However, if a system contains many individual convective cells, the precipitation efficiency of any one of them is likely to be of little more than academic interest, because the precipitation efficiency of individual cells could vary considerably across a large convective system. Note that $E$ is not necessarily a constant, but can be a function of space and time. Strictly speaking, in the relationship $R$ $=E w q$, all quantities have been averaged over the lifetime of a precipitating system.

Broadly speaking, therefore, calculation of a single cell's precipitation efficiency is of minor significance; what matters is being able to anticipate the efficiency in a general sense. How likely is it that the potential flood-producing storm is going to have high precipitation efficiency? Of the input water vapor in a convective storm, virtually all of it will condense, since a convective updraft is typically tall enough that the saturation mixing ratio at the storm top is on the order of $0.1 \mathrm{~g} \mathrm{~kg}^{-1}$. This value is roughly $1 \%$ of a typical input mixing ratio, implying that $99 \%$ of the input water vapor condenses. What happens to the condensed water vapor? Some of it falls as precipitation, some of the cloud particles are swept away by the winds aloft to evaporate elsewhere, and some condensate evaporates in downdrafts in the vicinity of the storm. In other words, that which does not fall as precipitation eventually evaporates. What promotes evaporation? There are some microphysical aspects to this question, involving such issues as the droplet size spectrum, the fraction of ice in the condensate, and so on. These currently are unobservable in the operational arena, and whatever role they might play is unknown to a forecaster.

Another factor in precipitation efficiency is the entrainment rate, since bringing environmental air that is unsaturated into a cloud tends to promote evaporation. This, too, is unlikely to be known by a forecaster, except in general terms: an isolated cloud is more likely to suffer substantial entrainment than a cloud embedded within a larger cloud system, since the environment of the latter typically is much more nearly saturated than that in the vicinity of an isolated cloud. This brings up the key observable factor related to evaporation: environmental relative humidity. As the relative humidity decreases, the evaporation rate increases and the precipitation efficiency falls. There can be other environmental factors, such as wind shear, that alter precipitation efficiency. Interested readers should consult 
Fankhauser (1988) for additional discussion about precipitation efficiency and the factors that might control it.

Thus, if at least one of the three factors $(E, w$, and $q$ ) for high rainfall rates is large (or likely to become large) while the other ingredients are at least moderate, the potential for high $R$ exists. Obviously, the potential for high $R$ increases as $E, w$, and $q$ increase and the relationship is multiplicative and, hence, nonlinear.

\section{b. Ingredients for deep, moist convection}

From the preceding, it should be clear why flash flood-producing storms are usually convective in nature. Deep, moist convection normally occurs during the warm season when high moisture content is possible and buoyant instability promotes strong upward vertical motions. Thus, the rainfall rates associated with convection tend to be higher than with other rain-producing weather systems. Precipitation efficiency typically is not an important issue unless there is reason to believe that it will be unusually low (as might be the case for high-based convection, e.g., over much of the interior Rockies). Therefore, although flash flood events of a nonconvective nature do occur (as we shall show), they are sufficiently uncommon that the search for flash flood potential generally begins with a search for the potential for convection.

Again using an ingredients-based approach, deep, moist convection ${ }^{3}$ is associated with buoyancy. This buoyancy virtually always arises because the lapse rate of a rising saturated parcel (i.e., ascending a moist adiabat) is less than that of the environment, so that the rising parcel eventually becomes warmer than its environment. This is simple parcel theory, of course; even with all its limitations, simple parcel theory is a powerful tool for anticipating deep, moist convection.

In order to produce buoyancy and deep convection, then, 1) the environmental lapse rate must be conditionally unstable, 2) there must be sufficient moisture that some rising parcel's associated moist adiabat has a level of free convection (LFC), and 3 ) there must be some process by which a parcel is lifted to its LFC. As discussed in Doswell (1987), the lift required to raise a parcel to its LFC generally must be supplied by some process operating on subsynoptic scales, because the rising motions associated with synoptic-scale processes usually are too slow to lift a potentially buoyant parcel to its LFC in the required time. We shall return to this topic later.

\footnotetext{
${ }^{3}$ The term "deep, moist convection" is used instead of "thunderstorm' 'because not all cases of the former involve lightning (and its associated thunder). We wish to avoid excluding nonthundering convection, so we are using the more general term.
}

When deep, moist convection is already under way, it is obvious that the ingredients are already in place. In situations where convection is not happening at forecast time, the forecasters must determine whether or not those ingredients will be in place at some time in the future. This involves assessing the possibility that the missing ingredient will become available, while the other ingredients will remain in place. Existing convection's future evolution should be considered in the same light: the existing convection will continue as long as the ingredients remain present and will cease when one or more of the ingredients is no longer favorable.

\section{c. The character of flash flood-producing storms}

We already have considered the topics related to rainfall rate, so the question of the rainfall associated with an event now becomes one of determining the duration. As noted by Chappell (1986), most important flash floods are produced by quasi-stationary convective systems, wherein many convective cells reach maturity and produce their heaviest rainfall over the same area. By this means, a convective event achieves a relatively long duration, since individual convective cells have lifetimes that almost always are too short to produce heavy rainfall even though the individual convective cell rainfall rates can be high.

For a convective system made up of a number of convective cells, the duration of the high precipitation rate in any location is related to 1) system movement speed, 2) system size, and 3) within-system variations in rainfall intensity. When a system moves very slowly, the other factors may not be very important for those locations that are experiencing the most intense rainfall in the system. For large systems, the duration of moderate or greater intensity rainfall can be quite long (Maddox 1983; Fritsch et al. 1986), regardless of the system movement speed. Nevertheless, as a general rule, flash floods are associated with slow-moving precipitation systems.

Obviously, system movement, denoted by the system motion vector $\mathbf{C}_{s}$, can affect the duration, but an Eulerian view requires knowledge of the system size along $\mathbf{C}_{s}$; denote this length by $L_{s}$. The idea is illustrated in Fig. 2; as already noted above, the rainfall total from the system is simply $\bar{R} D$, where now $D$ can be expanded to

$$
D=L_{s}\left(\left|\mathbf{C}_{s}\right|\right)^{-1} .
$$

Long duration is associated with systems that have a) slow movement, b) a large area of high rainfall rates along their motion vector, or c) both of these. A squall line with a large motion normal to the line will not produce long-lasting precipitation at any point (as illustrated by Fig. 3a), whereas the same line with the majority of its motion parallel to the line will take a 


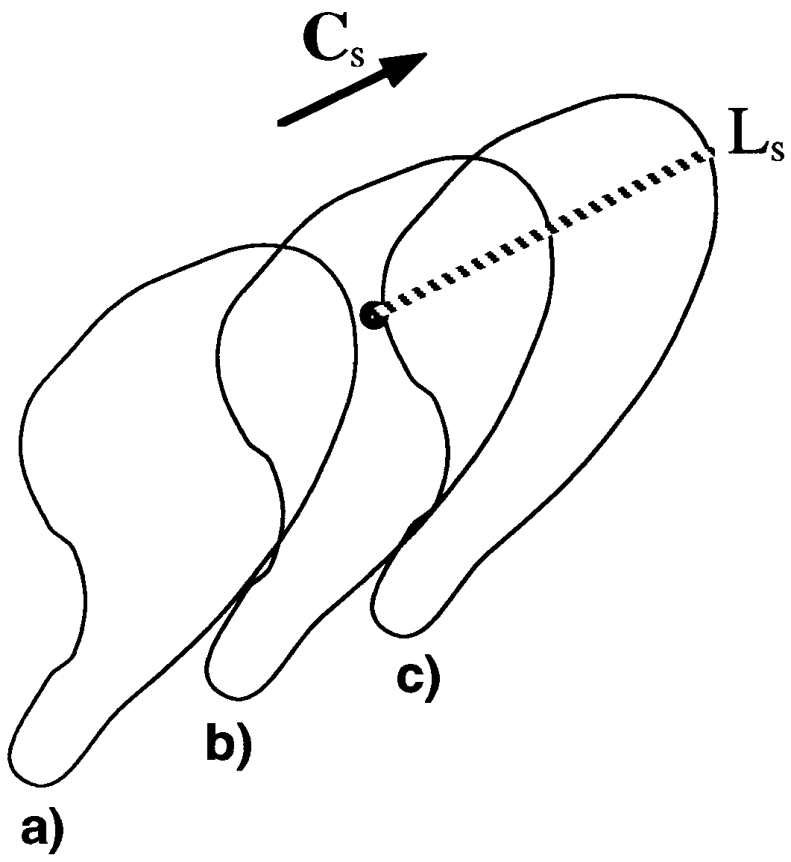

FIG. 2. Schematic illustrating the concept of the length of a system, $L_{s}$, as it passes a point. The system motion vector is denoted by $\mathbf{C}_{s}$, and the system is shown (a) as it first encounters the point, (b) halfway through the encounter, and (c) as it is leaving the point. For the asymmetric system shown, different points would have different values for $L_{s}$, and different orientations for $\mathbf{C}_{s}$ would yield different values for $L_{s}$ at the same point.

longer time to pass a point (as in Fig. 3b), resulting in more rainfall. Mesoscale convective systems with a large region of "stratiform', precipitation ${ }^{4}$ trailing a leading convective line may end up with a long duration of moderate-to-heavy rain showers following a relatively brief intense rainfall associated with the leading convective line, exacerbating the effect of the heavy rainfall (as illustrated in Fig. 3c). Obviously, the case where many intense convective cells pass in succession over the same spot, the so-called train effect, is the situation producing the highest rainfall totals (as in Fig. 3d).

Chappell (1986) indicates that convective cell movement, $\mathbf{C}_{c}$, is related to $\mathbf{V}_{m}$, the mean wind through some deep tropospheric layer (in which the cloud is embedded). Thus, slow system movement could be associated with weak winds. This is indeed the case on some occasions (e.g., Maddox et al. 1978; Maddox et al. 1979). However, having strong winds within the troposphere by no means excludes the potential for

\footnotetext{
4 The term "stratiform", may not be an entirely accurate description of the precipitation that trails behind a convective line within an MCS, but we will continue to employ it here in view of its widespread usage.
}

convective precipitation to have long duration at some given location. Convective system movement, $\mathbf{C}_{s}$, is the vector sum of the contributions from $\mathbf{C}_{c}$ and the socalled propagation effect, denoted by $\mathbf{P}_{s}$. In the context of convective storms, "propagation'" is the contribution to system movement from the development and dissipation of individual convective cells. A convective precipitation system is not a "thing" in the sense that it is an object made up of the same elements over some period of time, as a stick or a book is a thing. Rather, convective systems are processes made up of a number of subprocesses (convective cells), through which air parcels are flowing. It is the near cancellation of the cell movement via propagation effects that results in slow system movement (Fig. 4).

Anticipating cell movement is relatively simple, since cells generally move more or less with $\mathbf{V}_{m}$. That is, simple advection dominates cell movement in most cases. Forecasting the contribution from propagation is much more difficult, because the convection can interact with its environment to develop new convection in preferred locations relative to the existing cells. New convective development can be influenced heavily by the outflow boundary produced from the existing (and previous ) cells. This boundary is a storm-scale source of intense lift when the boundary-relative moist inflow is large. Strong boundary-relative flow can arise in two quite distinct ways: 1) ambient flow is weak but the boundary is moving rapidly, or 2) ambient flow is strong but the boundary is moving slowly. Obviously, only in case 2 can the duration of a convective event be large at a given location. Rapid boundary movement is virtually never associated with long-duration rainfall at a point.

Again speaking generally, the outflow location relative to an updraft is determined by the updraft-relative flow within the precipitation-bearing layer. Since precipitation forms in the middle and upper troposphere, the outflow usually is located downstream (in the updraft-relative framework) with respect to the middleand upper-tropospheric winds. The precipitation cascade region usually is under the anvil of a convective storm. An ideal situation for a long-duration convective rainfall event is when the cells move roughly parallel to a slow-moving outflow boundary, leaving a quasistationary segment of the boundary behind into which a substantial moist boundary-relative flow is impinging, creating new cells that repeat the motion of their predecessors. The new cells reinforce the boundary, maintaining its position against the inflow. Such a system can persist for many hours, as long as the moist, unstable inflow is maintained. The Johnstown, Pennsylvania, event (Maddox et al. 1979) was of this sort. In the Johnstown case, the southeastern part of the boundary and its associated convective line moved rapidly southeastward, while the northwestern part of the boundary remained quasi-stationary, and repeated new 
a.
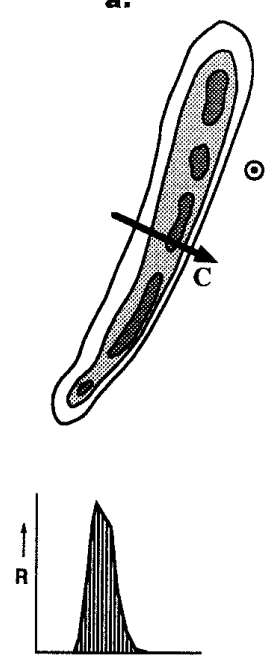

b.
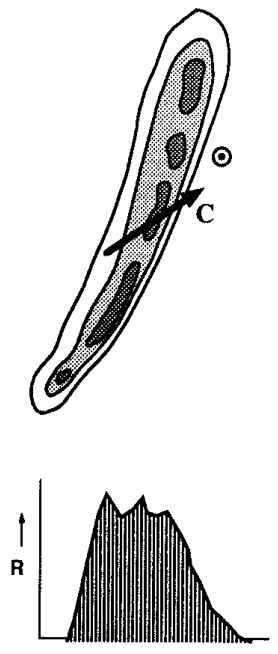

c.
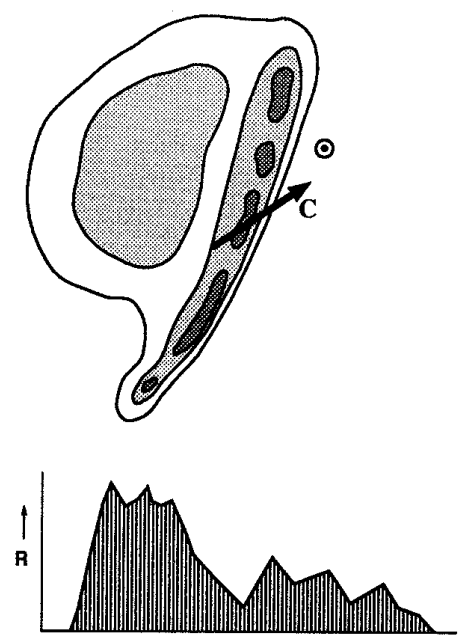

d.
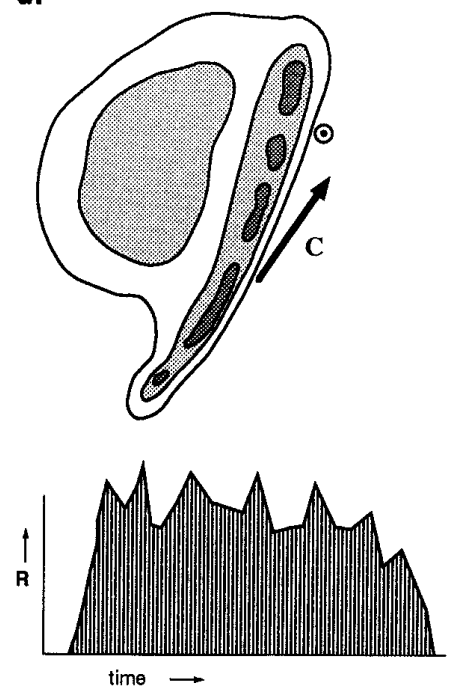

FIG. 3. Schematic showing how different types of convective systems with different motions affect the rainfall rate $(R)$ at a point (indicated by a circled dot) as a function of time; contours and shading indicate radar reflectivity. For case (a) a convective line is passing the point with a motion nearly normal to the line, for case (b) the line is moving past the point with a large component tangent to the line itself, for case (c) the line has a trailing region of moderate precipitation but is otherwise similar to (b), and for case (d) the motion of the line has only a small component normal to the line but is otherwise similar to (c). Total rainfall experienced at the point is the shaded area under the $R$ vs time graphs.

convective development along that part of the boundary produced the event.

We note that propagation can be affected by processes external to the convective storm itself. That is, features that have an independent existence prior to the development of the convection (such as fronts, old outflow boundaries, sea-breeze fronts, etc.) also can influence the development of new convective cells. These "external" factors need to be considered in anticipating system movement. As seen in Maddox et al. (1979), there are some synoptic/mesoscale patterns typically associated with flash floods, and it is clear that these patterns favor slow system movement. Recently,

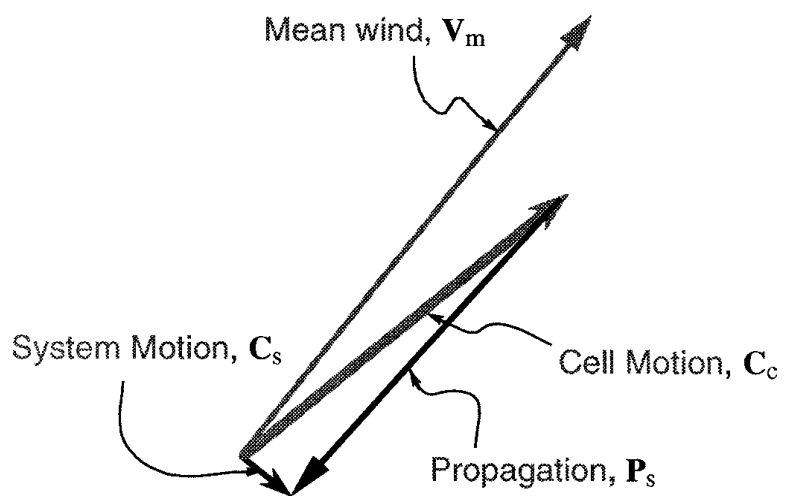

FIG. 4. Schematic showing the near cancellation between cell motion, $\mathbf{C}_{c}$, and propagation, $\mathbf{P}_{s}$.
Corfidi et al. (1996) have presented some concepts that appear quite promising for application to forecasting MCC movement. Irrespective of the processes by which it occurs, it is slow system movement that dominates most cases of flash flood-producing heavy precipitation, as observed by Chappell (1986).

\section{d. Flash flood-producing storm types}

Anticipating flash flood potential apparently requires one to know what storm types are likely to be involved. Unfortunately, categorizing convective storm types is a task replete with pitfalls ( see Doswell 1991); it can be difficult to do operationally. If classification of ongoing events is difficult, it is even more difficult to forecast what storm types are likely. Johns and Doswell (1992) have offered an ingredients-based approach to forecasting severe weather-producing convection; their methodology is predicated mostly on the importance of supercell storms in severe weather. As we shall try to show in what follows, however, heavy precipitation can be associated with a wide variety of storm types. A full treatment of this topic is simply beyond the scope of this paper, and it is not yet clear that the science has progressed to the point where anticipating storm types is likely to be straightforward.

In developing this classification, it is important to recognize that the process is sensor dependent. The storm structure seen from the perspective of a geostationary satellite can be quite different from that seen by 
a radar. We shall present classifications based on both these perspectives.

\section{1) Multicell CONVECtion}

The notion that convection can be classified into single-cell, multicell, supercell, and squall line structures goes back at least to the seminal papers by Marwitz $(1972 a, b, c)$. This is primarily a radar-based perception. There is a growing awareness, however, that single-cell convection is mostly unimportant and relatively rare; a single cell consists of a single "bubble" of buoyant parcels, and the typical deep, moist convective storm is made up of a number of such bubbles, even though its radar echo can give the appearance of a single entity. The vast majority of isolated radar echoes that persist for many lifetimes of a single cell $(\sim 20$ min) are multicell events. To say that a storm is multicellular is basically to provide little, if any, information about its nature. Thus, we are proposing that the "'multicell" classification offers little or no value simply because most convection is multicellular, even supercells (see below) and squall lines. Most flash floodproducing convection, therefore, is multicellular, but this knowledge is not helpful if virtually all convection is also multicellular.

Of particular importance, however, is the degree of organization associated with the multiplicity of cells. If the new cells tend to form in a preferred location relative to the old cells, then the convective system can propagate in a coherent fashion, which clearly is of importance to the problem. Generally speaking, convective organization is a complex topic involving the interaction among updrafts, downdrafts, and the environmental conditions, as we have noted.

\section{2) SuPERCELl CONVECTION}

Given sufficient observational resolution, supercells typically exhibit multicellular aspects, so we do not consider a supercell to constitute a single-cell event (see Doswell and Burgess 1993). What is important about supercells in the context of flash floods is their tendency to have strong updrafts. By virtue of their interaction with the environment, such storms can have a substantial contribution to their updraft from dynamic (nonbuoyant) vertical accelerations (Rotunno 1993). Supercells also tend to have significant low-level moisture associated with their environment, so the combination of intense updrafts and substantial low-level moisture suggests some potential for heavy rainfall rates.

Typical supercell environments have two general characteristics that mitigate against heavy rainfalls, however. The "loaded gun" sounding classically associated with supercells (denoted as a "Type I' sounding by Miller 1972) is characterized by a dry lower midtroposphere, thereby suggesting a significant reduction in precipitation efficiency due to evaporation. This is accentuated by the isolated character of most supercells, potentially enhancing entrainment. Further, typical supercell environments often are associated with high wind speeds aloft, resulting in significant supercell motion, even if their motion is slower than the mean tropospheric wind.

There are some supercells, nevertheless, that appear to produce prodigious precipitation (Moller et al. 1990; Doswell and Burgess 1993; Moore et al. 1995) in spite of the likelihood of low precipitation efficiency for most supercells. The 4 June 1980 case documented by Maddox and Doswell (1982) is an example of a supercell producing a flash flood event. Later in its life cycle, this storm evolved into a mesoscale convective system, a not uncommon evolution. These so-called high precipitation (HP) supercells have significant flash flood potential; unfortunately, a methodology for forecasting them has yet to be developed. Brooks et al. (1994) have suggested some ideas that might be useful for forecasting HP supercells, but these ideas have yet to be validated. Another aspect of concern, of course, is the storm motion; there is as yet no reliable technique for forecasting storm motion accurately (see Doswell et al. 1992). Thus, we recommend using something simple for supercells like $30^{\circ}$ to the right of the mean wind at $75 \%$ of the mean wind speed (as proposed in Davies and Johns 1993) for estimating supercell storm motion, since more sophisticated methods seem not to give a reliable significant improvement over simple techniques, at least on average.

\section{3) Squall Lines (RADAR)}

As the low-level outflow from convection spreads out in a pool of precipitation-cooled air, it tends to be the locus for development of new updrafts. The general tendency for convection to form in lines is almost certainly associated with this characteristic. Outflow boundaries enhance any existing lifting processes (such as fronts, drylines, or orography) that might cause the initial convection to be organized in lines. Moreover, the outflows from neighboring convective cells can merge to form an extensive pool of outflow along which new convection develops. If convection exhibits any organization at all, it frequently is a linear structure, so many flash flood-producing convective events exhibit this characteristic. The train effect (as described in section 2c) where cells form and pass repeatedly, in succession, over the same location results from a linear organization.

What matters, of course, is the movement of organized convective lines on many occasions. When the linear structure is associated with synoptic-scale processes, such as fronts, the speed of movement of those processes tends to be closely matched to the speed of 
movement of the convection. The prototypical flash flood-producing synoptic patterns proposed by Maddox et al. (1979) exemplify this characteristic, as we have noted. Not all synoptic systems move slowly, of course, and in such situations, the convective systems forced by the large-scale processes also move relatively quickly, minimizing the flash flood threat.

\section{4) Mesoscale convective systems}

Maddox (1980) was the first to describe the large, persistent mesoscale convective structures (e.g., Fig. 5 ) that can arise. In developing the early studies of those systems, he proposed a set of criteria to define what he called "mesoscale convective complexes" (MCCs). That definition was intended to limit the study to consideration of only the largest, most persistent, most nearly circular cold cloud shield members of a spectrum of convective systems, in part because of the limited resolution of standard observational systems (as shown on Fig. 5). However, this definition is not meant to imply that there is something qualitatively distinct about MCCs versus other mesoscale convective systems (MCSs) that fail to meet one or more of the criteria. Further, this categorization of convection is based solely on satellite-observable characteristics. Since persistent convection is inevitably multicellular in character, almost any persistent convective system will develop a substantial anvil, thus making it appear as an MCS on satellite, with the anvil size (and, hence, the satellite-observed classification) depending on updraft strength and the number of convective cells. Virtually all flash floods are produced by MCSs, although the cloud tops may not meet one or more of the essentially arbitrary criteria commonly associated with systems classified as MCSs; in particular, they may not develop cloud-top equivalent blackbody temperatures that are cold enough to meet particular MCC/MCS criteria. This is an example of an important problem with essentially any set of arbitrary threshold criteria for categorizations: important events that are created by the same physical processes characterizing the members of some class of events may not always meet the criteria to belong to that class. Simply because a convective system has a relatively warm top does not mean that the physical processes by which heavy precipitation is produced by that system are different from those processes operating in a system with a criterion-satisfying cold top.

It has been amply demonstrated in many studies of MCSs (e.g., Houze et al. 1989; Smull and Weisman 1993; Loehrer and Johnson 1995) that systems meeting MCS criteria have their convection arranged in a more or less linear fashion as seen on radar. To the extent that MCCs and MCSs contribute to flash flood events (see Fritsch et al. 1986), this implies that a radar depiction of those events would probably show a linear organization in many cases. Such MCSs have a trailing "stratiform" precipitation region that can contribute to the storm precipitation totals and exacerbate the flash flood threat by a prolonged period of moderate rainfall that follows the initial, shorter duration period of the most intense precipitation.

MCSs can contribute to a special sort of evolution that can combine river floods with flash floods, as in the summer of 1993 over the northern Mississippi and Missouri River Valleys. In such situations, the MCSs play a role comparable to individual convective cells in an MCS. That is, MCSs form repeatedly over a period of days (or even weeks) in roughly the same area and traverse the same path. This situation has been described by Belville and Stewart (1983) for events in and near Louisiana and by Doswell (1985) in more general terms. The repetitive passage of MCSs makes the flash flood threat from later event passages greater than from the first MCS, owing to the soaking of the ground and consequent increased runoff.

\section{5) SQuall lines (Satellite)}

As viewed from a satellite (Fig. 6), some MCSs take on what is clearly a linear structure over large scales. Whereas MCSs with more nearly circular cold cloud tops may have a linear structure on radar, what appear as "squall lines" on satellite may or may not have a predominantly linear structure on radar. Individual convective systems within such an extensive line can include relatively isolated storms as well as radar-observed squall lines. It is typical for satellite-observed linear structures to be associated with synoptic scale boundaries (e.g., fronts). Although there is no a priori reason to assume that such structures move relatively rapidly, it appears to be uncommon for satellite-observed squall line-type MCSs to produce flash floods.

\section{6) NONCONVECTIVE PRECIPITATION SYSTEMS}

Although most flash flood events are produced by deep, moist convection, for the reasons already noted, there are situations where one can develop the proper ingredients in a nonconvective situation. That is, the strong updrafts leading to heavy precipitation are forced rather than freely buoyant. Probably the most common way in which this occurs is for the vertical motion to be forced by orography. Whether upward motion is free or forced makes no difference as far as the atmosphere is concerned; moist air ascending condenses and produces precipitation in essentially the same way, although the (currently unobservable) microphysical aspects of the process might differ. Often, forced uplift does not attain the heights associated with free convection, so the precipitation-producing cloud tops may not be very cold. Low-topped precipitation systems clearly will affect the satellite depiction of an 


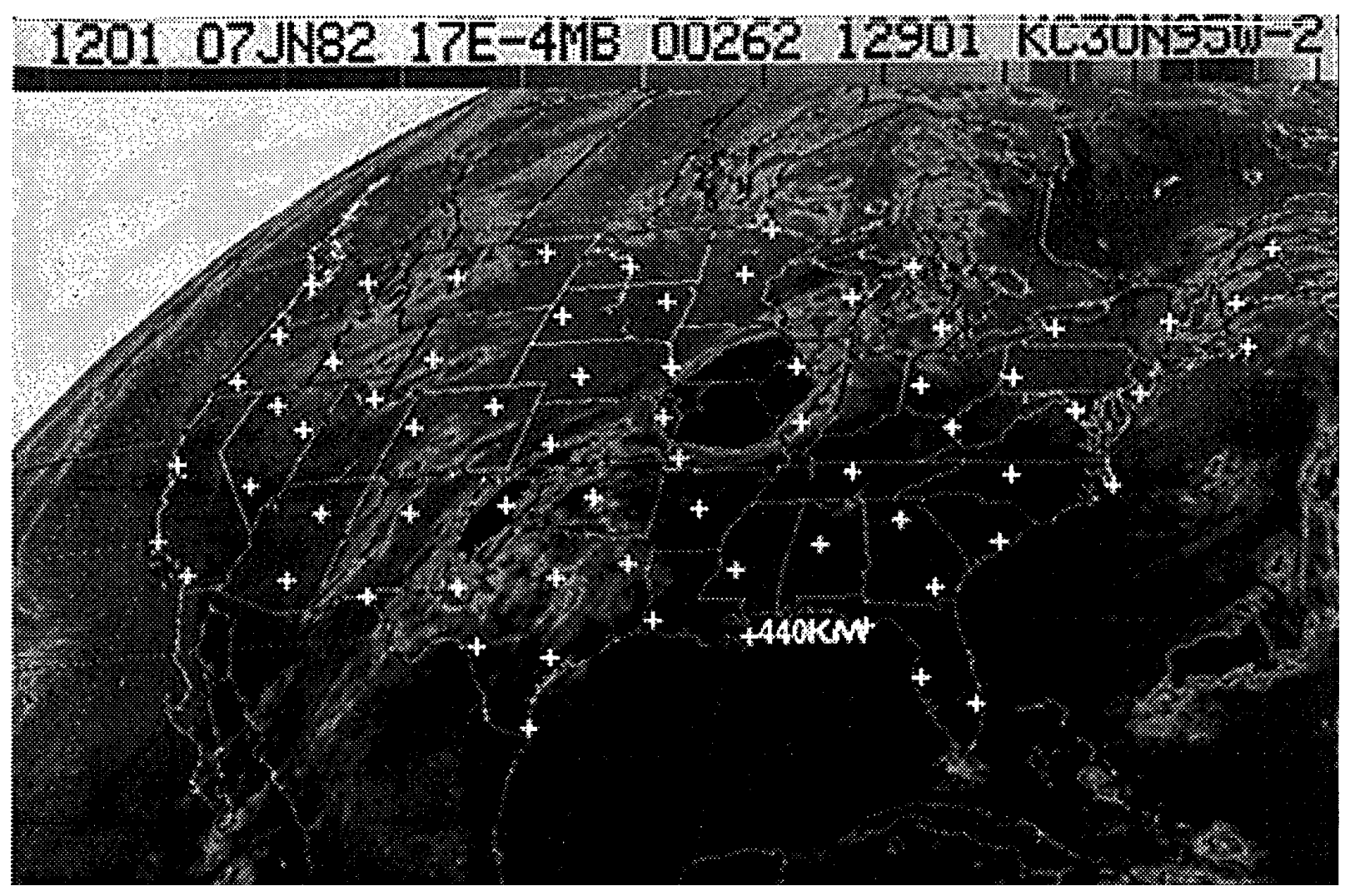

FIG. 5. Satellite image of mesoscale convective complex over Missouri, Illinois, and Iowa. The crosses indicate the routine rawinsonde site at the time of the image, showing the size of the system relative to the upper-air sounding network.

event and can be a factor in the capability of radar to detect the event as well, notably at long ranges from the radar.

Ignoring the challenge to radar in situations involving complex terrain, the interpretation of radar in terms of precipitation amounts typically has been through a so-called $Z-R$ relationship, where $Z$ is the observed radar reflectivity and $R$ is the rainfall rate. In general, $Z-R$ relationships vary in space and time, even during a single event (Brandes 1975) and certainly can change from case to case. Although radar is a potentially powerful tool in depicting precipitation, it has some limitations and may not always give a reliable quantitative estimate of precipitation. What is important is to recognize the potential in the meteorological analysis of the situation, so that when precipitation commences, detection of an important rainfall event does not depend only on a literal acceptance of the quantitative precipitation estimates from the radar.

\section{Meteorological processes concatenating ingredients}

The scope of this paper does not permit an extensive discussion of the practice of meteorological analysis in operations ( see Doswell 1982, 1985 for a lengthy treatment), but we must emphasize the notion that anticipation of the possibility of a flash flood event is critical to handling the situation properly in practice. A flash flood is a rare event in any one location, and most forecasters will not be on duty during a killer flash flood event at any time in their careers. Unlike conventional forecasting, opportunities to practice the procedures for dealing with a flash flood event come too infrequently for forecasters to develop much experience with them. The forecaster almost always has to get it right the first time. Training exercises can help, but it is up to the forecaster to recognize that a particular day is going to be "the big day" and not just another rainy day.

Flash flood event days often are not manifestly different from the nonevent days that preceded them. The difference between a rather nondescript day and a terrible flash flood situation may not be obvious even at the time of the morning soundings on the fateful day. Ingredients are usually not clearly in place and together in the morning; if they were, the event would be imminent or already under way. Overreliance on "indices" can be fatal in this circumstance, because indices are keyed to detecting conditions that are already in place, which might not be the case in the morning. 


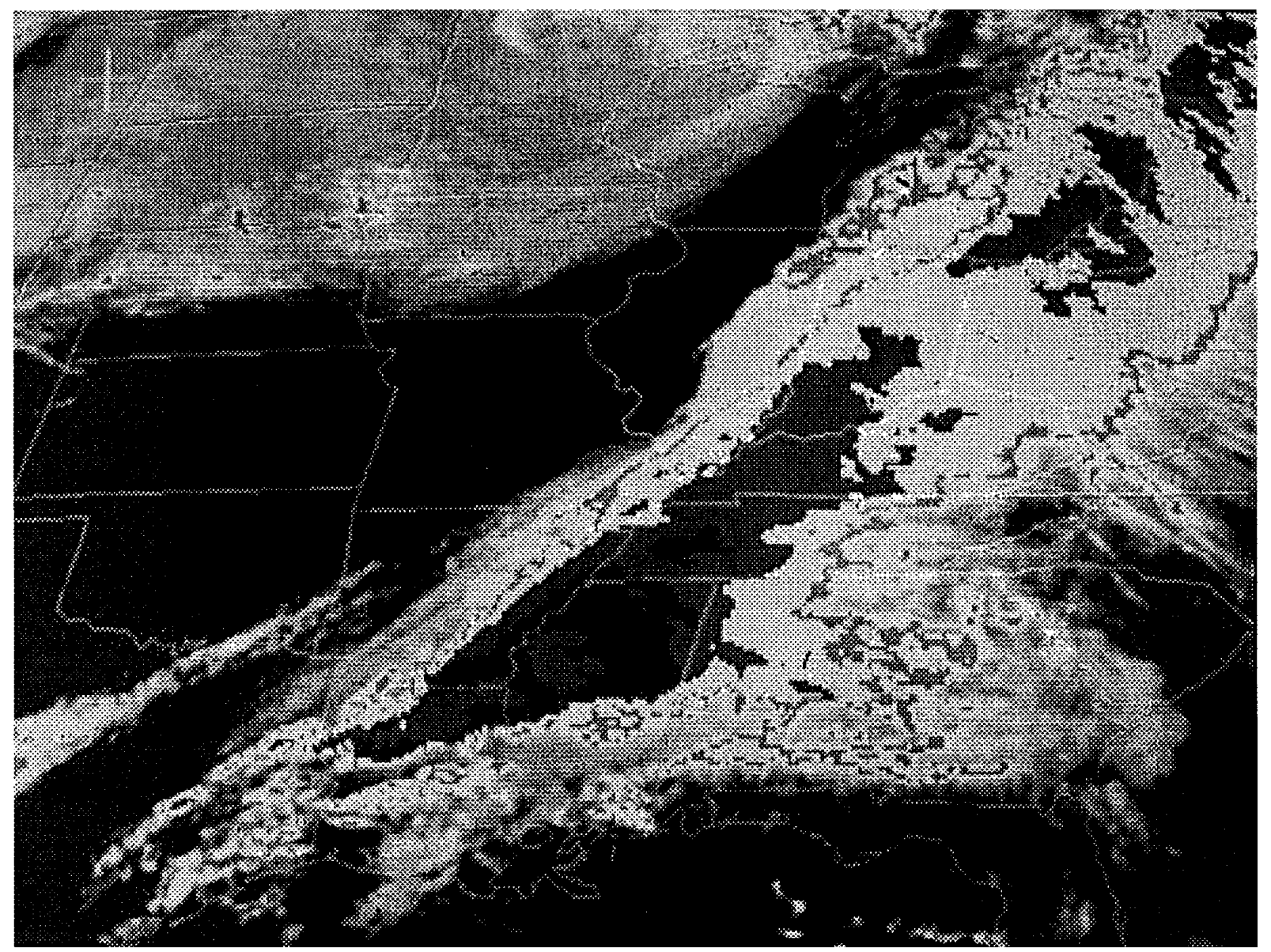

FIG. 6. Satellite image of linear mesoscale convective system.

This is a potentially dangerous situation for a forecaster, if a superficial look at the data (such as that given by an index) creates an illusion of security. In many flash flood disasters, we have seen that an inability to recognize the potential inherent in a meteorological situation causes a reduction in vigilance and a lack of focus on the important details. In this section, we want to describe the contributions of meteorological processes on various scales to flash flood events in the terms we have already given: those factors leading to heavy precipitation.

\section{a. Large-scale processes}

Although we have pointed out that large-scale vertical motions typically do not provide the lifting necessary to initiate convection, there is an unmistakable connection between synoptic-scale weather systems (i.e., short-wave troughs) and deep, moist convection. Doswell (1987) has suggested that the connection is via the moistening and destabilization created by the modest but persistent synoptic-scale vertical ascent ahead of short-wave troughs. The presence of a synoptic-scale weather system necessitates adjustments between mass and momentum that can be approximated reasonably well by a quasigeostrophic analysis, although the important details may be tied to nonquasigeostrophic mesoscale processes that are difficult to diagnose and forecast in detail. As exemplified by Lanicci and Warner (1991) for the southern plains of the United States, the passage of synoptic weather systems creates a fairly regular sequence of events in any given geographic area. Approaching systems have more or less predictable basic structures, based on their evolution up to the point of the forecast, and the numerical weather prediction (NWP) models may have a reasonably accurate diagnosis and prognosis of those systems. Unfortunately, as observed by Antolik and Doswell (1989), the NWP models have their best success when the situation is dominated by synoptic-scale weather systems.

Further, many flash flood events arise in what are superficially benign synoptic conditions. The important aspects of flash flood cases can be subtle and may es- 
cape attention if forecaster vigilance has been decreased by days of relatively inactive weather. Maddox et al. (1979) note that many flash flood events occur near a synoptic-scale 500-mb ridge axis, a region not always identified as a locus for important weather events. This apparently anomalous activity may be a direct consequence of the suppressing effect of the anticyclone. That is, the synoptic-scale subsidence occurring with the ridge aloft tends to suppress deep convection and enhances diabatic heating processes that can contribute substantially to increasing the lapse rate (Doswell et al. 1985). This suppression of convection also allows the return of moisture at low levels; deep, moist convection can consume moisture at a rate far greater (by about an order of magnitude) than can be supplied by synoptic-scale processes ( see Fritsch 1975; Fritsch et al. 1976). If convection is to persist any length of time on any given day, then it usually is processing accumulated moisture that most likely would not be present if deep, moist convection had already been occurring. This process of accumulation over many hours is why it is atypical for convection to occur continuously at a given location: it takes hours for the synoptic-scale processes to resupply the area with moisture. During an extended episode, such as the summer of 1993, the convection of a particular day tends to die off ${ }^{5}$ for several hours before redeveloping later the next day, allowing the synoptic flow and diurnal heating to reaccumulate the needed ingredients for another round of convection.

The initiation of convection in association with a synoptic-scale anticyclone or ridge typically occurs on the margins of the suppressed area, where sharp thermal boundaries often exist. This leads to the so-called ring-of-fire effect, in which active convection surrounds the zone of most intense synoptic-scale suppression.

\section{b. Mesoscale processes}

We have noted that a major role for mesoscale processes is to provide the lifting needed for convective initiation. Although the needed lift may be related to processes on scales even below that normally considered "'mesoscale," one typically must begin the search for candidate mechanisms on the mesoscale. At times, this can be quite difficult, as the routine datasets available in operations may not permit this task to be straightforward. The role of mesoscale terrain, an important lifting mechanism when the flow is upslope, also must be considered.

\footnotetext{
${ }^{5}$ The well-known tendency for flash floods to occur after dark means that the convection can persist well into the night but usually dies off late in the morning of the next day. Redevelopment then takes place during the late afternoon.
}

Moreover, mesoscale processes are not limited to developing the lift needed to initiate convection. Mesoscale processes associated with MCSs can be responsible for heavy precipitation events in a number of ways. First, they can influence system propagation, as in the Johnstown, Pennsylvania, event of 1977 (Hoxit et al. 1978). Second, their typical organizational structure, described by Loehrer and Johnson (1995), involves both a deep convective part and a so-called stratiform part. Recalling Chappell's rule for heavy precipitation, the deep convective portion of the MCS can contribute a very high rate of precipitation for a relatively brief time during the passage of the system, whereas the region of trailing, moderate precipitation can produce a long duration to the overall precipitation event (as seen in Fig. 12 of Hoxit et al.). Third, such MCSs often produce large pools of outflow that persist for many hours after the rain-producing convection itself has dissipated. Such outflow boundaries often play a vital role in the initiation of subsequent convection, which in turn may develop into a slow-moving MCS, as described in Chappell (1986). When the outflow pools are heated by insolation, they can destabilize rapidly, with some contribution to destabilization coming through evaporation of the precipitation deposited by the preceding system. By affecting the windflow over relatively large areas, moreover, MCSs can change the wind shear of the "environment" in which new convection develops, affecting the likelihood of a particular convective event producing heavy precipitation.

Relatively little is known about the nonconvective mesoscale processes that might contribute to convection. Clearly, unobserved mesoscale processes may be responsible for some "surprise" events, wherein it appears that the ingredients for a heavy precipitation event are not in place and yet the atmosphere does, indeed, produce such an event. This argument is an appealing one, but it carries with it the risk that its invocation can mask ignorance of the real processes leading to a particular event. In other words, the absence of clear indications of what we think is going on is "explained away" by calling on some unseen mesoscale process. This may be correct, but it is a basically unscientific argument, since it presupposes an explanation in the absence of any evidence. Nevertheless, it is likely that on some occasions, unobserved low-level moisture or midtropospheric high lapse rates or some other apparently missing ingredient can at times actually be present due to mesoscale processes unseen via the available observations.

\section{c. Storm-scale processes}

Once deep convection is under way, the evolution of the convective event can be modified significantly by the convection itself. A major contributor to how the convection behaves is the outflow created by convec- 
tive downdrafts. If the storm evaporates ${ }^{6}$ a great deal of condensate, this produces a significant chilling of the air that, in turn, creates negative buoyancy. By and large, most strong downdrafts are associated with this process ( see Johns and Doswell 1992), and so the likelihood that a convective storm will develop a cold outflow is associated with the "evaporation potential" of its environment. Of course, high evaporation rates also are associated with low precipitation efficiency. As noted already, flash flood cases can arise with low precipitation efficiency, but that factor must be compensated for by high input water vapor content and/or strong vertical motion.

If we suppose that the evaporation potential is at most moderate, or perhaps low, then the outflow should not be so cold that it tends to move rapidly away from its source (the precipitation cascade region of the convective storm). This means that new convective cells, perhaps initiated along the storm's outflow, can be in relatively close proximity to predecessor cells. This begs the question of the relationship between an existing cell and its precipitation cascade. Where will the precipitation cascade be relative to the updraft? If a forecaster is to be able to anticipate the contribution of propagation to the overall system motion, then it must be possible to forecast the development of new convective cells; if not, then it would be impossible to obtain a forecast of when convective storm systems would become quasi-stationary, except in cases where they are tied to a terrain feature.

What is needed for predicting the updraft-relative precipitation cascade location? Consider the following simple "thought experiment." Suppose a garden hose is directed straight up in a completely calm environment. This means that the water spray simply will fall back directly onto the upwelling stream. Now imagine a windy day, and suppose that the wind is constant with height. On such a day, the water spray clearly will be advected downstream by the wind. But suppose that the hose could be carried along with the exact speed and direction of the wind. Obviously, the water spray again would fall back upon the stream again. Therefore, the location of the water spray in this simple example is determined by the relative windflow, in a framework moving with the source of the spray.

In a convective cloud, precipitation forms aloft within the cloud, near or above the freezing level. In accordance with our thought experiment, this means that the wind relative to the source of the precipitation

\footnotetext{
${ }^{6}$ The term "evaporation" is being used here to include all forms of phase change that take up heat and chill the air in the process: evaporation, melting, and sublimation. There are many unknowns about the contribution of ice phase condensate to the overall development of convective drafts and their associated inflows and outflows.
}

in the updraft will determine the location of the precipitation cascade with respect to the updraft. In an environment with strong vertical wind shear, it is impossible for a convective storm not to have storm-relative flow at some levels through its depth; unless the updraft is being tilted strongly by the sheared flow, the updraft has only a single motion vector, $\mathbf{C}$. Therefore the storm-relative wind, $\mathbf{V}_{r} \equiv \mathbf{V}-\mathbf{C}$, vanishes only at levels where $\mathbf{V}$, the environmental wind vector, equals $\mathbf{C}$.

Situations in which the environmental shear is weak tend to have their precipitation cascade located close to the updraft. This means that if the low-level outflow is not so strong that it undercuts the updraft (thus removing its source of low-level moisture and instability), new cells can develop close to the existing cells. However, the very proximity of the precipitation cascade can make the cells vulnerable to being undercut by outflow. For such cases, the outflow's undercutting tendency is reduced when the outflow is relatively weak; weak outflow is promoted by high relative humidity environments, due to reduced evaporative potential.

In situations with strong shear, the precipitation cascade can be several kilometers or more from the updraft. This separation can reduce the potential for the outflow to undercut the updraft, but it may mean that new cells develop a considerable distance from their predecessors. Some displacement of new convection from previous cells is helpful, but too much displacement means that new convection is essentially unconnected to and, hence, unaided by previous convection. In attempting to deduce the likely position of the precipitation cascade, it seems clear that forecasters need to examine the wind profile in detail.

As already noted, individual convective updrafts tend to move with a speed and direction roughly comparable to the mean wind in the tropospheric layer containing the updraft; cells simply are advected along (more or less) in the mean windflow. Figure 7 illustrates that the effect of cell movement and storm propagation can be in opposite directions, resulting in a nearly stationary storm. This interaction between advection and propagation is how quasi-stationary storms arise. Hence, as part of the considerations necessary to forecast a heavy precipitation event, the location and strength of the outflow (as it affects propagation) becomes a major issue. In fact, this topic is quite complex and is outside the scope of this paper; it is affected by many factors, such as rear-inflow jets, internal dynamical factors in convective systems, etc. (e.g., Weisman $1993)$.

\section{Case study examples}

\section{a. Iowa, 8 September 1989}

The heavy rain event that struck Iowa in September 1989 provides a good example of many of the problems 

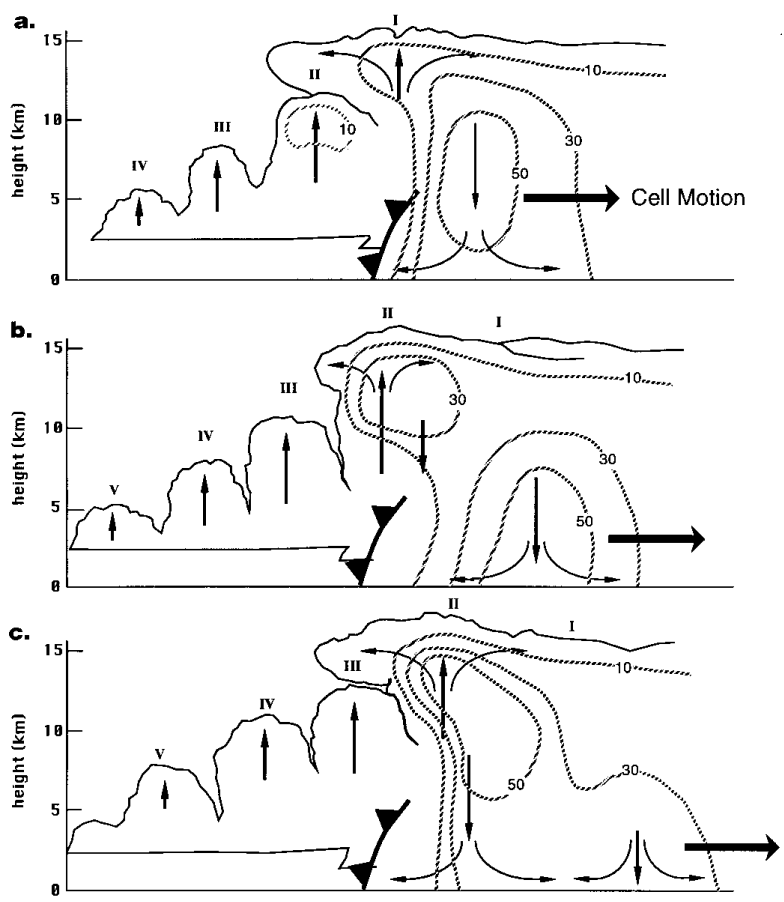

FIG. 7. Schematic showing three stages in the evolution of a multicell thunderstorm system. Cells are labeled with Roman numerals (I, II, III, etc.); thin arrows indicate the updrafts, downdrafts, and divergence at the storm top and the surface associated with each cell the frontal symbol indicates the low-level outflow boundary; the cell motion is indicated by the heavy arrow; and hatched lines show radar reflectivity and are labeled in $\mathrm{dBZ}$. Note that the cells are moving left to right while the outflow boundary remains fixed in place.

associated with the subtleties of flash flood forecasting. In particular, by considering the day before as well, it shows the subtle differences that can exist between a "'nonevent" day and an "event'" day, as well as illustrating the effects of antecedent precipitation and hydrology on the impact of a heavy precipitation event.

The evolution of the large-scale synoptic situation over the central United States was slow, as illustrated by the $500-\mathrm{hPa}$ maps at 0000 UTC on 7 and 8 September 1989 (Fig. 8). Even though low-level flow was weak, the advection of warm, moist air north and northeastward into Iowa throughout the period slowly eroded a strong capping inversion that had been present on 7 September. Since advection takes place along isentropic surfaces, not on isobaric surfaces, this process is best seen as part of an isentropic analysis (Fig. 9). The impact of this rather slow large-scale process on the thermodynamic structure of the atmosphere over 24 $\mathrm{h}$ is actually quite noticeable, but might be difficult to notice using simple indices. The inversion in the Omaha sounding that limited convection on the evening of 6 September and the morning of 7 September (Fig. 10a) is higher and much weaker by 0000 UTC on 8 September (Fig. 10b). Also, the low-level mois- ture has increased and deepened into a layer almost 150 $\mathrm{hPa}$ thick, increasing the precipitable water from 37 to $48 \mathrm{~mm}$. The lifted index has decreased very slightly from $-7.1^{\circ}$ to $-7.3^{\circ} \mathrm{C}$, and the total totals index has changed only from $52.7^{\circ}$ to $52.1^{\circ} \mathrm{C}$ (a very minor change, but opposed in sign to the change in the lifted index ). This illustrates one danger associated with depending on indices that rely heavily on mandatory levels for their information. In contrast, the convective available potential energy (CAPE) has increased from 3050 to $4300 \mathrm{~J} \mathrm{~kg}^{-1}$, while the convective inhibition has decreased from 140 to $8 \mathrm{~J} \mathrm{~kg}^{-1}$.

The CAPE values indicate pure adiabatic parcel theory peak ascent rates exceeding $90 \mathrm{~m} \mathrm{~s}^{-1}$. Such peak ascent rates probably are not actually observed in real convective storms, but when average updrafts of even one-third that magnitude are combined with large input mixing ratios (on the order of $15 \mathrm{~g} \mathrm{~kg}^{-1}$ ), prodigous rainfall rates are quite plausible.

An MCS produced heavy precipitation overnight on 7-8 September. There were three areas in Iowa that officially received more than $100 \mathrm{~mm}$ ( 4 in.) in the 24 h ending 1200 UTC 8 September 1989, with a maximum of about $180 \mathrm{~mm}$ (7.2 in.; Fig. 11). Afternoon convection had produced an outflow boundary (Fig. 12) oriented northwest-southeast across southwestern Iowa. Given the wind profile (Fig. 10b), with westerly flow dominating above $700 \mathrm{hPa}$, eastward movement of convective cells is likely. New cells would form near the cold front-outflow boundary intersection in western Iowa as the low-level flow (enhanced perhaps by the nocturnal boundary layer wind maximum) brings in abundant moisture [surface dewpoints exceeding $\left.21^{\circ} \mathrm{C}\left(70^{\circ} \mathrm{F}\right)\right]$ to impinge on the boundaries. Thus, a near cancellation of the effects of advection and propagation would result in a slow-moving MCS. The ingredients (high rainfall rates and long rainfall duration) had been assembled for substantial rainfalls overnight.

Although street and basement flooding occurred in many locations, damage was minor in rural areas, in large part because of extremely dry conditions that had persisted for the previous 2 yr. Thus, despite it being a significant meteorological event, the hydrological situation limited the damage. If the antecedent precipitation had been normal or above normal, the effects of the heavy precipitation might have been much worse.

\section{b. Moapa Valley, Nevada, 10 August 1981}

Much of the western United States, with its mountainous terrain, is particularly susceptible to flash flooding. Forecasting the exact location of any individual event is difficult, but identifying the potential for a general area is possible. An example of using simple tools to identify potential areas of concern is the 1981 Moapa Valley, Nevada, flood.

At 1200 UTC 10 August 1981, the atmosphere over southern Nevada was characterized by high lapse rates 

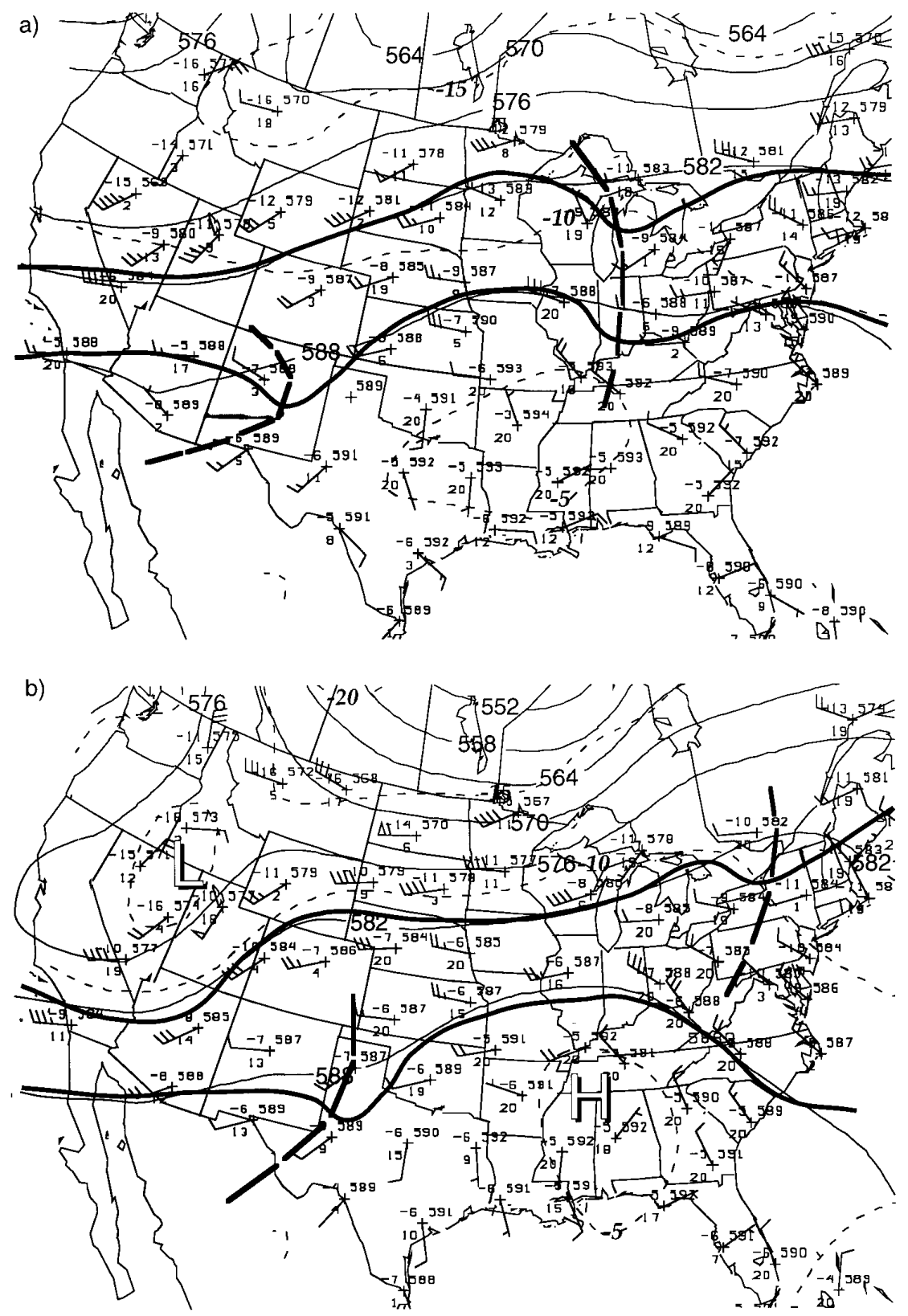

FIG. 8. 500-hPa maps for 0000 UTC on (a) 7 September 1989 and (b) 8 September 1989. Objectively analyzed height fields are the solid lines with plain text labels (contour interval 60 dam), and temperature fields are the dashed lines with italic labels (contour interval $5^{\circ} \mathrm{C}$ ). The 5880- and 5820-m contours have been adjusted subjectively (thick solid lines) and short-wave trough axes indicated (thick-dashed lines).

(temperature difference between 700 and $500 \mathrm{hPa}$ greater than $24^{\circ} \mathrm{C}$ ) and substantial low-level moisture (Fig. 13). Note how the regions of maximum lapse rate and moisture are offset rather than coincident, a typical structure. When high lapse rates and moisture coincide, some process usually provides enough lift to produce deep convection that rapidly eliminates the region where they overlap, so having them coincide is generally a transient situation (Doswell et al. 1985). Having large amounts of low-level moisture $(q)$, combined with steep lapse rates implies substantial CAPE is possible, which, in turn, implies large vertical motions $(w)$ in deep convection. Thus, high rainfall rates $(R)$ are possible; recall that $R=E w q$. 
a)

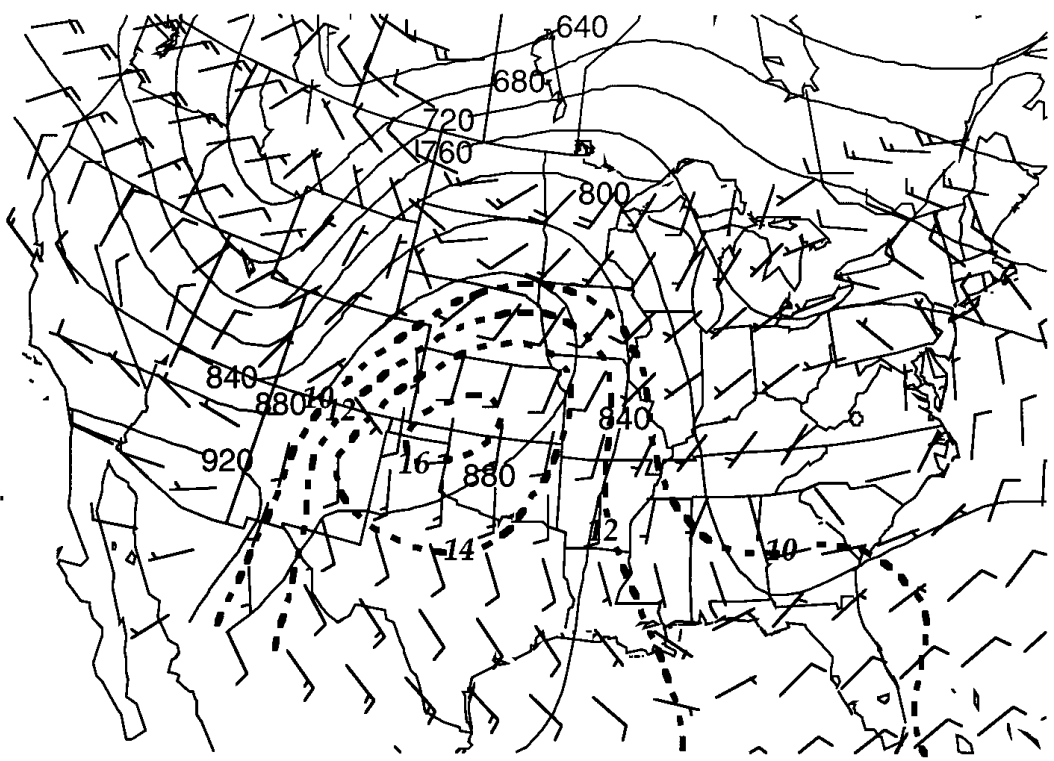

b)

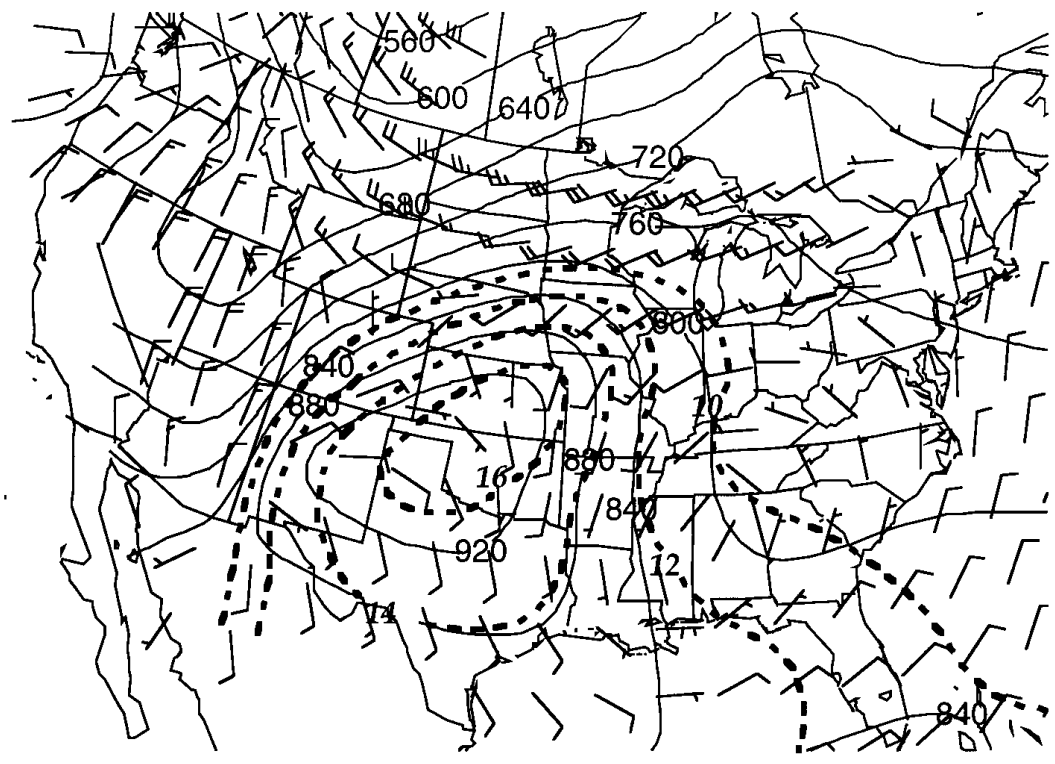

FIG. 9. Isentropic analysis of pressure (solid lines, contour interval $40 \mathrm{hPa}$ ) and mixing ratio (dashed lines, contour interval $2 \mathrm{~g} \mathrm{~kg}^{-1}$, beginning at $10 \mathrm{~g} \mathrm{~kg}^{-1}$ ) on the $306-\mathrm{K}$ surface at 0000 UTC on (a) 7 September 1989 and (b) 8 September 1989, overlaid with the wind barbs.

Late in the afternoon, storms formed along an eastwest line across southern Nevada in association with a surface boundary that provided a lifting mechanism. Individual cells moved relatively slowly along the boundary, as the east-southeasterly mean wind in the cloud-bearing layer shown in the hodograph from Desert Rock, Nevada (Fig. 14), suggests. Bucket surveys indicate precipitation amounts up to $165 \mathrm{~mm}$ (6.5 in.) fell in about $1 \mathrm{~h}$ northeast of Las Vegas (National Weather Service Western Region Headquarters 1982) (Fig. 15). The resulting flood along the California
Wash killed 500 cattle at the Hidden Valley Ranch and caused approximately $\$ 3$ million in damages.

\section{c. Kenai Peninsula, Alaska, 9-11 October 1986}

Deep convection is not a prerequisite for heavy precipitation, even though it is the most common mechanism. Under the right conditions, orographic lift can lead to prodigious rain accumulations in nonconvective environments. Moderate precipitation rates $(R)$ combined with long duration $(D)$ also can develop flash 

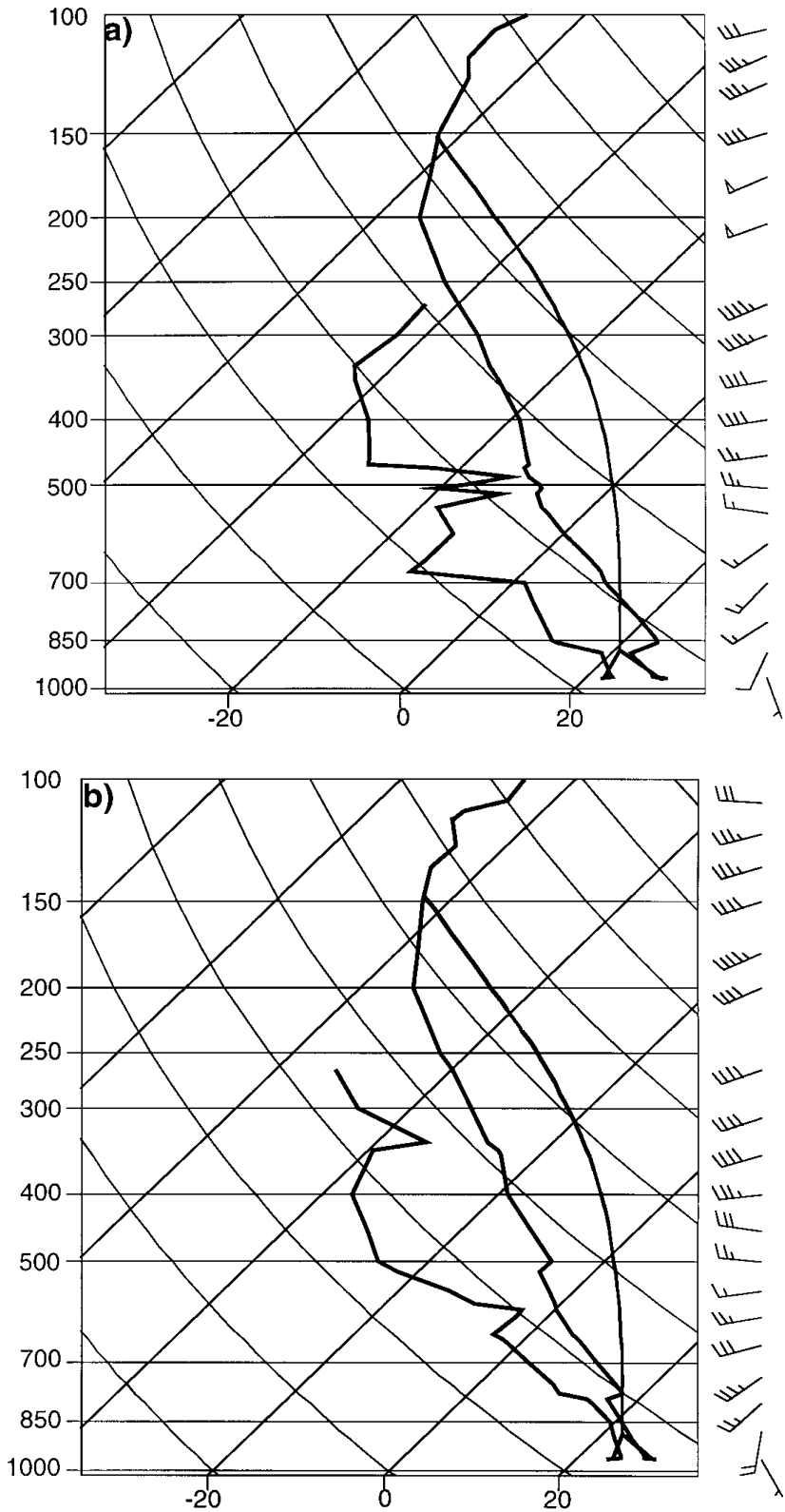

FIG. 10. Thermodynamic profiles from Omaha at 0000 UTC on (a) 7 September 1989 and (b) 8 September 1989; a mixed parcel ascent is indicated on both soundings.

flood potential. As an example, over $450 \mathrm{~mm}$ of rain ( $\sim 17.5$ in.) fell in 2 days on the Kenai Peninsula, south of Anchorage, Alaska, in October 1986 (Fig. 16). The topography of the Kenai is dominated by a mountain range with peaks of about $1500 \mathrm{~m}$ running along the length of the peninsula. That range served as the primary location for mechanical lifting and subsequent heavy precipitation in this case.

A strong synoptic-scale system moved slowly from the west toward southern Alaska during the period, ad- vecting climatologically high moisture values (20-25 $\mathrm{mm}$ or more of precipitable water, compared to an October mean of $11 \mathrm{~mm}$ ) toward the Kenai on 15-30 $\mathrm{m} \mathrm{s}^{-1}$ southerly winds in the lower troposphere. The terrain gradients, combined with strong synoptic-scale upslope flow, suggest forced updrafts along the slopes on the order of $50 \mathrm{~cm} \mathrm{~s}^{-1}$ or more. The slow movement of the system allowed the strong winds to persist for $48 \mathrm{~h}$ at the Anchorage (ANC) sounding site (Fig. 17). Thus, moderate $w$ and $q$ values produced moderate rainfall rates that were sustained for 2 days.

This case also provides an excellent example of moisture depletion of the low-level air as it passes over a mountain barrier, provided that ascent leads to precipitation. The sounding from ANC at 12 UTC 10 October 1986 is notably drier $(7 \mathrm{~mm}$ less precipitable water) than the upstream sounding taken from Kodiak (ADQ) at the same time (Fig. 18). Despite this moisture loss, the ANC sounding still has twice the normal October precipitable water value, and additional heavy precipitation was observed as the air again experienced topographically forced ascent north of Anchorage (Fig. 16). Indeed, the precipitation accumulation for this event is closely related to the regions of orographic lift. The case emphasizes how forecasting precipitation amounts in complex terrain can be dominated by the interaction between synoptic-scale processes and mesoscale terrain features.

\section{Discussion}

To summarize briefly, we have suggested that every flash flood event shares some basic ingredients. In order

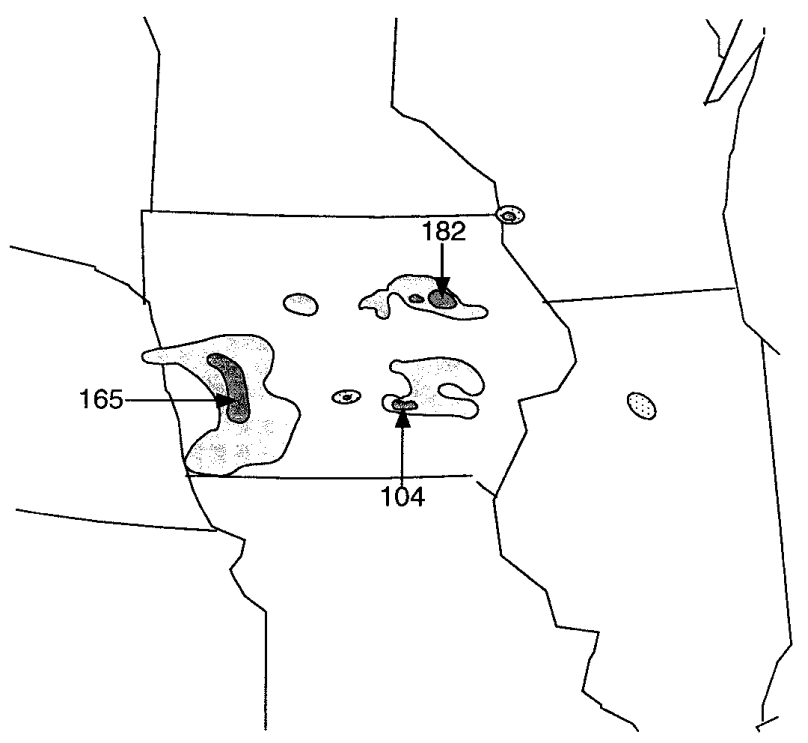

FIG. 11. Analysis of the 24-h precipitation ending 1200 UTC 8 September 1989 over Iowa, with contours at 25 and $75 \mathrm{~mm}$. Local maxima are indicated, with values in $\mathrm{mm}$. 


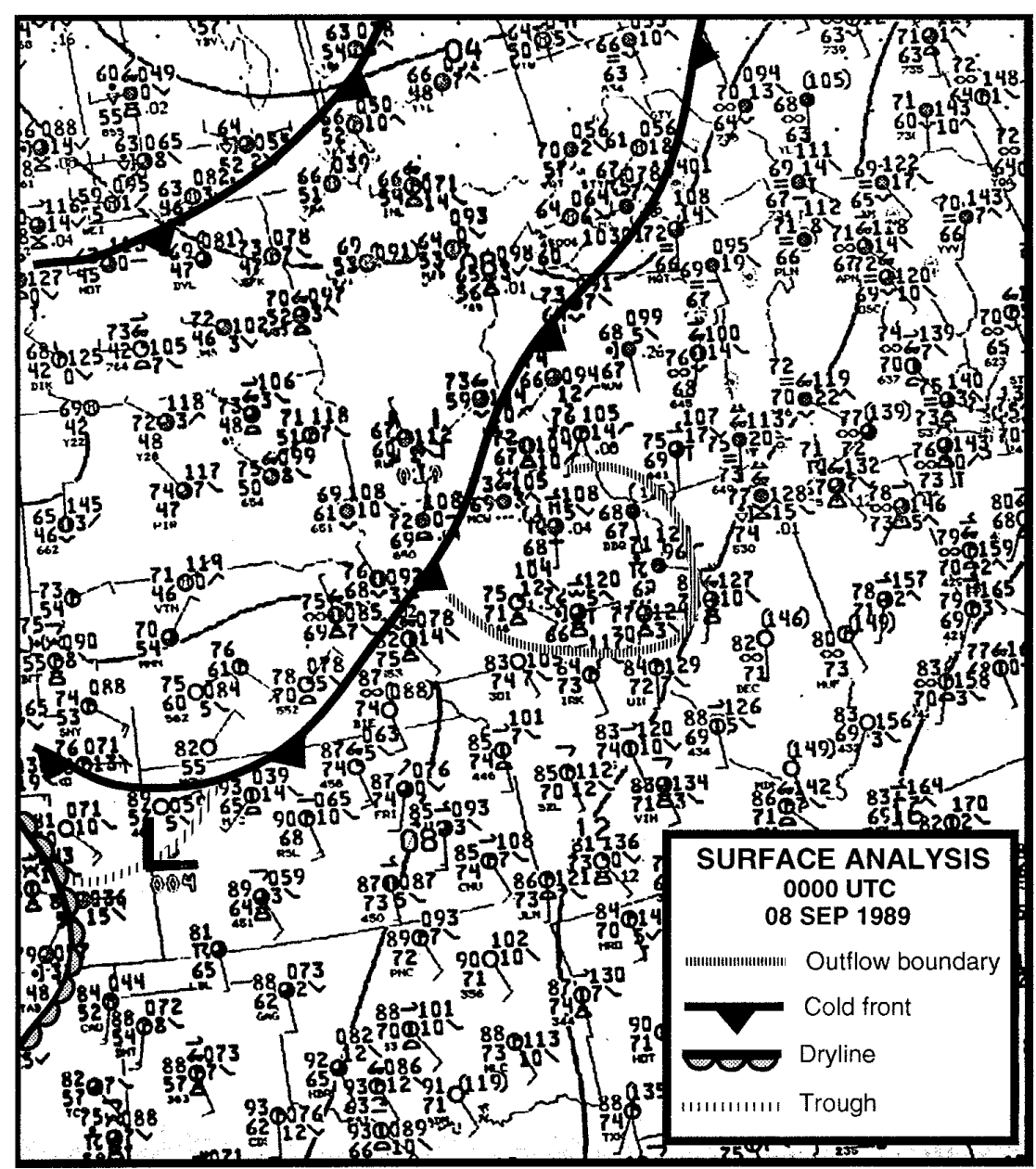

FIG. 12. Surface analysis at 0000 UTC 08 September 1989: analysis boundaries identified in the key, solid lines are National Meteorological Center objectively analyzed isobars (contour interval $4 \mathrm{hPa}$ ). Surface dataplots are conventional.

for a flash flood to occur, heavy precipitation must fall in a region that has appropriate hydrological ingredients in place. The hydrological ingredients have not been dealt with in detail in this paper, but include such topics as antecedent precipitation, topographic relief, land use, and so on. In order for heavy precipitation to occur, high rainfall rates must be sustained. High rainfall rates, in turn, result from rapid ascent of moist air. Long duration of high rainfall rates results from slow movement of the rainfall-producing system. We have illustrated that these ingredients can be assembled in a variety of circumstances, most of which can be identified with deep, moist convection.

Forecasting based on ingredients is, of course, not limited to flash flood forecasting. No matter what the forecast event is (e.g., a tornado, fog, or freezing rain), the same or similar simple notions can be applied. In operational practice today, it is common for forecasters to use a variety of different approaches, often driven primarily by personal preferences. Any of these approaches (e.g., sound meteorological principles, relying on model output statistics, rules of thumb, pattern recognition, etc.) might have their own virtues and vices. We believe that an ingredients-based methodology is a logical choice for the application of scientific understanding to the forecasting task. Using what is known about the processes leading to a weather event is the basis for developing a list of necessary ingredients. As we have noted, the knowledge can be focused more precisely to the forecasting task when scientific understanding is matched to the observations; knowledge without real-time observations of variables pertinent to that knowledge is not of much value in forecasting.

A large fraction of the events we call "weather" involve the ascent of moist air, leading to clouds, pre- 


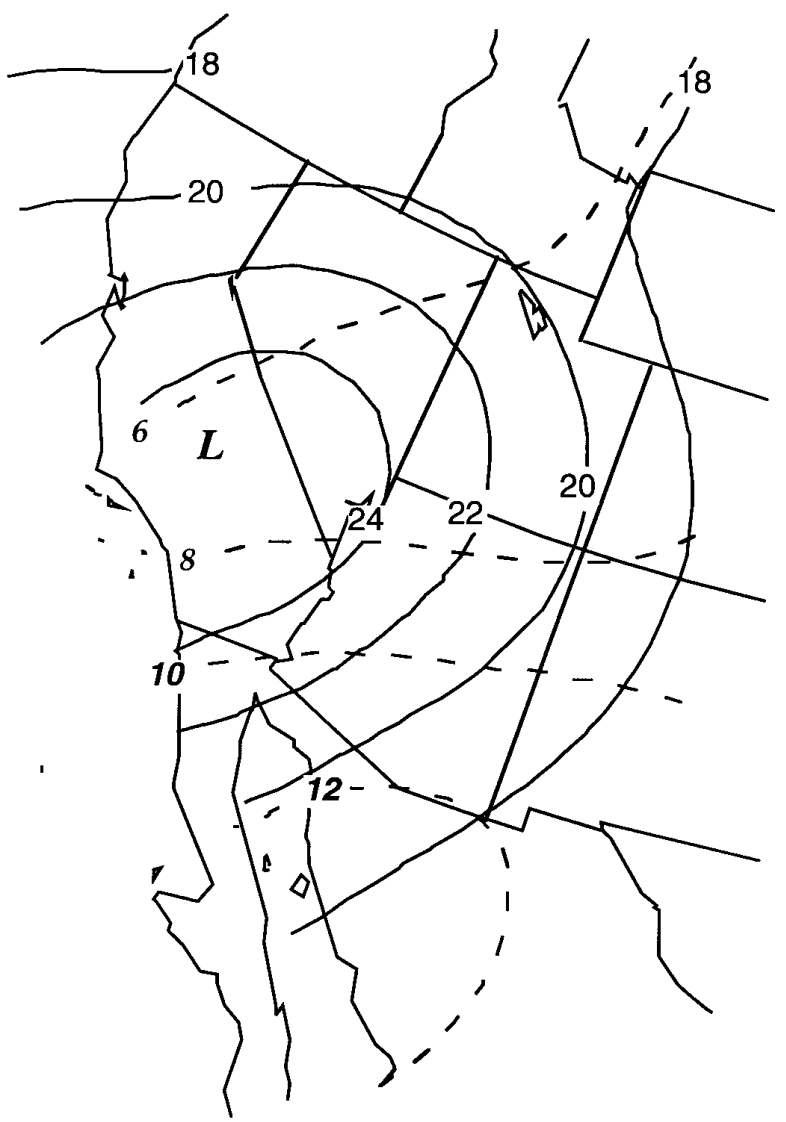

FIG. 13. Analysis of the 700-500-hPa temperature difference (contour interval $2 \mathrm{C}$; solid lines, plain text labels) and the $850 \mathrm{-hPa}$ mixing ratio (contour interval $2 \mathrm{~g} \mathrm{~kg}^{-1}$; dashed lines, italic labels). A surface low over California is indicated by the "L." All features are valid at 1200 UTC 10 August 1981.

cipitation, and convection. Therefore, forecasting meteorological processes contributing to the ascent of water vapor is a key element in many forecasts. ${ }^{7}$ Geographical variations in the processes, case-to-case differences, or temporal evolutions during the same case all contribute to a bewilderingly large number of aspects to consider in forecasting. The proliferation of diagnostic capabilities ${ }^{8}$ makes the current task of selecting what to look at in formulating a forecast a real challenge. This challenge is complicated further by the proliferation of different model forecasts to examine.

\footnotetext{
${ }^{7}$ Reducing "weather" to ascending water vapor is, naturally, a dramatic oversimplification and there are many weather elements that do not require ascent of moisture, but using this simple idea does illustrate how one begins the task of developing an ingredients-based methodology.

${ }^{8}$ It is interesting to observe that the operational forecaster currently has a greater choice of diagnostic tools to examine model output data than for the evaluation of observed data.
}

To a greater extent than ever before, a forecaster has to make choices, and uniquely personal ones at that, about which diagnostic and prognostic tools to use. The new tools are both liberating and inhibiting. Giving forecasters a wide range of choices can be liberating, since it offers the opportunity for individuals to explore what is most useful to them personally. But it potentially can inhibit the capacity for forecasters to interact among themselves, if their common grounding in certain charts and tools diminishes. Further, it can lead to a sense of bewilderment simply because of the vast array of choices to be made; nagging worries might arise about having overlooked some important chart or forecast guidance product.

When forecasting methods are scientifically based, the common ground is the science of meteorology, so the diagnostic and prognostic tools of choice must remain within those bounds. By focusing on ingredients, forecasters can reduce the range of their choices. If the models suggest the presence of ascending water vapor, a key question is the thermodynamic environment in which that ascent takes place. In certain situations, deep convection ensues; in others, it might be freezing rain or snow, or simply overcast skies. Thus, once ascending water vapor is given, the resulting events often depend on the vertical atmospheric structure at the location of the ascent. In a very real sense, the various weather map patterns in which the event occurs are not very relevant to the forecast. A quite similar pattern in another case might not produce the event at all, or the event might be of much reduced magnitude, perhaps because of different topography or slight variations in the thermodynamic environment, etc.

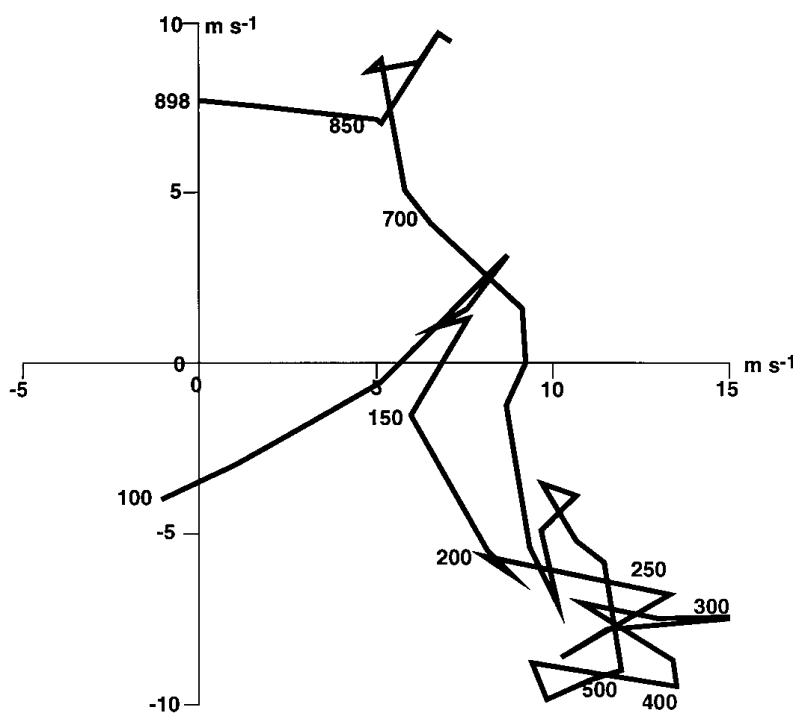

FIG. 14. Hodograph from Desert Rock, Nevada, 11 August 1981, with axes in $\mathrm{m} \mathrm{s}^{-1}$. Labels along the hodograph indicate the pressure in $\mathrm{hPa}$ at the levels along the hodograph next to the labels. 


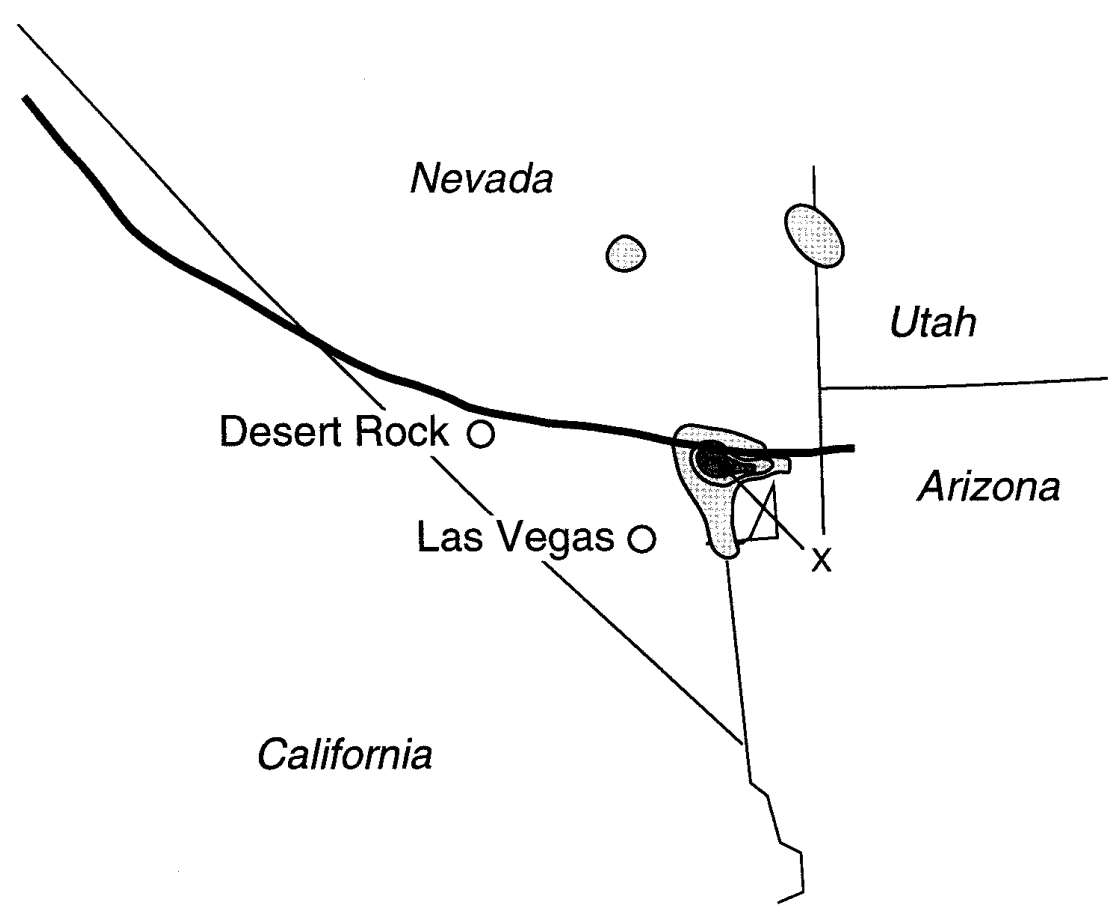

FIG. 15. Precipitation analysis for southeastern Nevada for Moapa Valley flood, 10 August 1981; the contour interval is $25 \mathrm{~mm}$, with the lowest contour $25 \mathrm{~mm}$. A heavy line designates the approximate location of the convective line at 2346 UTC, as shown by satellite imagery (not shown), which also coincides with the location of a frontal boundary in the surface analysis (not shown). The $\times$ and arrow show the location of the heaviest precipitation observation, 6.5 in. $(165 \mathrm{~mm})$. Las Vegas and Desert Rock are shown for reference.

Once it is determined that an event is possible, based on a forecast of the necessary ingredients, a number of important questions follow. Is the forecast scenario re-

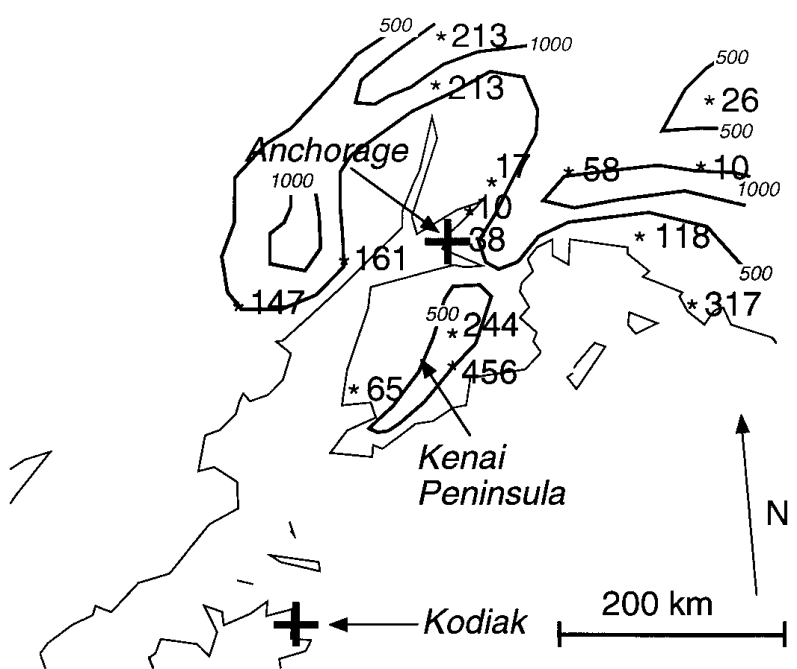

FIG. 16. Precipitation totals in $\mathrm{mm}$ for 9-11 October 1986 in southern Alaska. Anchorage, Kodiak, and the Kenai Peninsula are indicated for reference. sulting in heavy precipitation potential plausible? What are the processes resulting in concatenation of the ingredients? How plausible are the forecasts of those processes? These questions suggest which diagnostics, among the myriad candidates, are the ones to use in the development of a forecast.

We have illustrated this methodology using flash flood forecasting and shown some limited case study presentations to attempt to focus on how the ingredients for a flash flood can be diagnosed and anticipated. Space simply does not permit a sufficiently detailed presentation about the cases to show how it might work in operational practice. Offering a single, detailed case study might convey the false impression that the particular scenario chosen for presentation by which the ingredients are brought together represents some sort of "prototype" evolution for the case. In fact, we are strenuously opposed to any too-literal interpretation of the prototypical patterns presented in papers such as Maddox et al. (1979). Literal acceptance of prototypes can lead forecasters to reduce their perception of an event's likelihood when the pattern confronting them on a particular day is not an accurate match for some prototype.

We also observe that using prototypes often leads to false alarms because of the mesoscale meteorological 
intricacies described above. In any single case, the thread that connects all such prototypical patterns is the set of necessary ingredients for the event. The actual map patterns are not important by themselves; their only importance lies in their assembling of the ingredients for the event. As noted by Bosart and Lackmann (1995), a particular meteorological evolution can occur in a pattern that does not resemble the "standard" patterns at all. If a synoptic-mesoscale situation assembles the ingredients for an event, then the implied event is likely, irrespective of how uncommon it might be that those ingredients would be assembled that way. Any slavish adherence to prototypes can lead to detection failures as well as false alarms.

Obviously, if a forecaster is to focus on ingredients and processes, it is paramount that he or she understands the physical principles governing the event. This is not necessarily easy. Indeed, our collective understanding as a scientific community of many significant weather processes involved in flash floods is far from complete. However, the foregoing discussion indicates that forecasters will need to be well educated about the

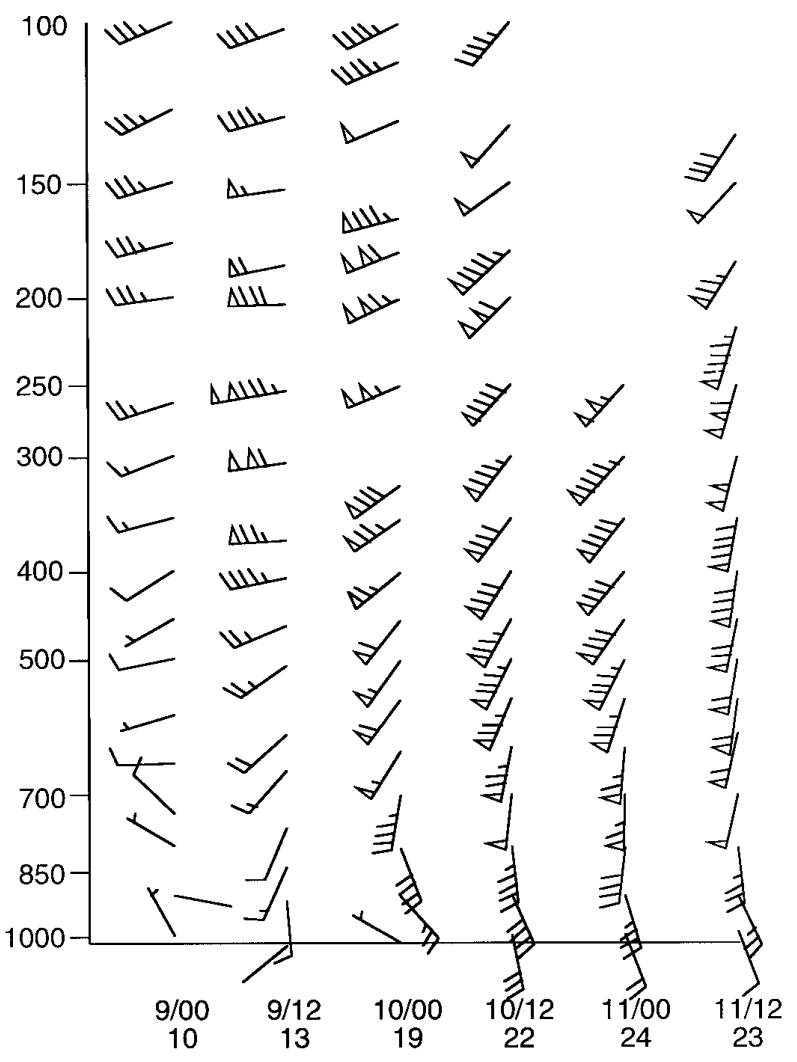

FIG. 17. Time-height cross section of sounding winds from Anchorage, Alaska, 9-11 October 1986. Full barbs are $10 \mathrm{kn}$ (5.1 $\left.\mathrm{m} \mathrm{s}^{-1}\right)$ and half barbs are $5 \mathrm{kn}\left(2.55 \mathrm{~m} \mathrm{~s}^{-1}\right)$. The numbers below the cross section indicate sounding date and time (UTC) and precipitable water in $\mathrm{mm}$.

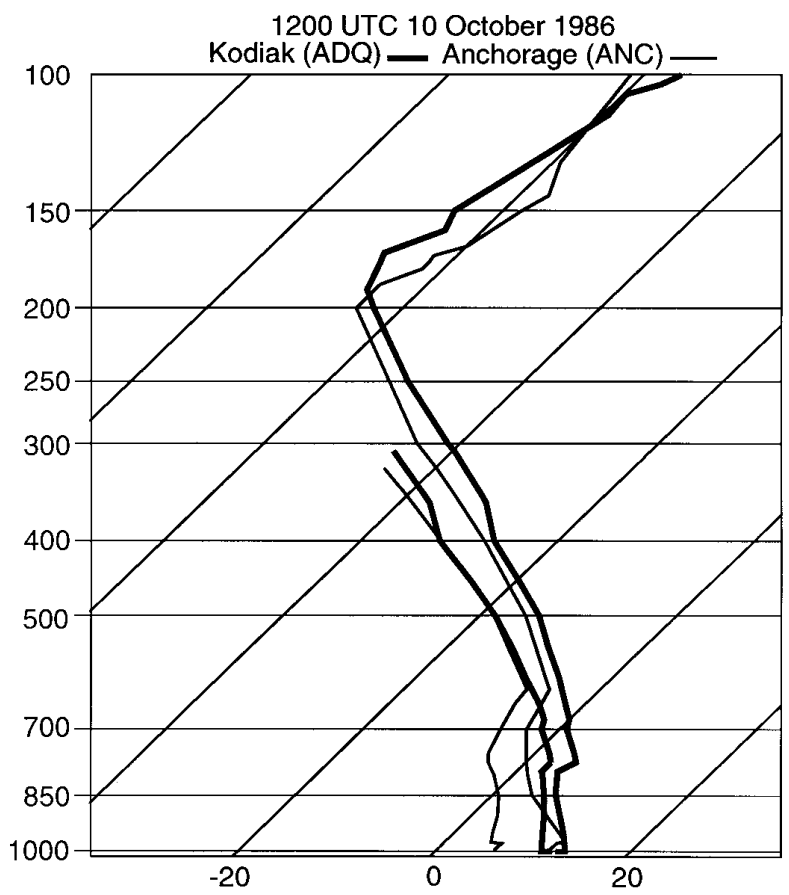

FIG. 18. Thermodynamic profiles from Kodiak (ADQ, heavy line) and Anchorage (ANC, light line) at 0000 UTC 10 October 1986.

behavior of the atmosphere and well trained to use that knowledge in forecasting. As hazardous weather is emphasized more in the future in the National Weather Service (NOAA 1991), the weather issues of importance are going to involve rapidly changing threats and, often, subtle changes in the atmosphere leading to those threats. As a result, forecasters first must be educated, and then trained, to meet the challenges of forecasting weather events that are necessarily hard to forecast. The importance of those forecasts for the public, however, means that education and training must, to a greater extent than is the case at the current time, form the heart of the forecaster development process in the future.

Acknowledgments. We wish to thank Mr. Ken Howard of NSSL for providing some of the maps used during the analysis of the case studies. We also appreciate the helpful suggestions and ideas that have come from attendees at the Flash Flood Forecasting Course at the National Weather Service Training Center. Mr. L. Giordano and two anonymous reviewers contributed many helpful suggestions for improving the presentation.

\section{APPENDIX}

\section{Details of the Determination of Precipitation Efficiency}

Precipitation efficiency, $E$, as defined in the text, is given by 


$$
E=\frac{m_{p}}{m_{i}}
$$

The mass of water vapor moving into a volume at any instant involves the time rate of change of water vapor mass within the volume. The total input over the life of a precipitation system will be the time integral of that time rate of change. By standard continuity arguments, this means that the input water vapor mass, $m_{i}$, is given by

$$
m_{i}=\int_{T}\left[\iiint_{\Sigma} \nabla \cdot(\rho q \mathbf{V}) d x d y d z\right] d t
$$

where $\Sigma$ is the volume containing the system, $\rho$ is the air density, $q$ is the mixing ratio of the air, $T$ is the life cycle time of the precipitation system, and $\mathbf{V}$ is the three-dimensional wind vector. By similar reasoning, the precipitation produced by the system is simply

$$
m_{p}=\int_{T}\left(\iint_{A} \rho_{w} R d x d y\right) d t
$$

where $R$ is the rainfall rate (in units of length per time), $\rho_{w}$ is the density of water, and $A$ is the area over which rain fell during the system lifetime. An important challenge in doing a precipitation efficiency calculation is to define the volume of integration, $\Sigma$, in (A2) and the area of integration, $A$, in (A3). The volume should contain the entire precipitation system, which means that part of the volume will be filled with downdrafts and outflow. By Gauss's divergence theorem, (A2) can be rewritten as

$$
m_{i}=\int_{T}\left[\iint_{S}(\rho q \mathbf{V})_{n} d \sigma\right] d t
$$

where $S$ is the surface (closed) bounding $\Sigma, d \sigma$ is an area element on that surface, and the subscript $n$ denotes a vector component normal to the surface. The input is the average (net) flux of water mass through the surface bounding the volume. If one chooses to define a volume following the system, then the velocity vector used in (A2) or (A4) should be converted to a reference frame following the system.

\section{REFERENCES}

Antolik, M. A., and C. A. Doswell III, 1989: On the contribution to model-forecast vertical motion from quasi-geostrophic processes. Preprints, 12th Conf. on Weather Analysis and Forecasting, Monterey, CA, Amer. Meteor. Soc., 312-318.

Belville, J. D., and G. A. Johnson, 1982: The role of decision trees in weather forecasting. Preprints, Ninth Conf. on Weather Forecasting and Analysis, Seattle, WA, Amer. Meteor. Soc., 7-11.

_ , and N. O. Stewart, 1983: Extreme rainfall events in Louisiana: The "New Orleans" type. Preprints, Fifth Conf. Hydrometeorology, Tulsa, OK, Amer. Meteor. Soc., 284-290.

Bosart, L. F., and G. M. Lackmann, 1995: Postlandfall tropical cyclone reintensification in a weakly baroclinic environment: A case study of Hurricane David (September 1979). Mon. Wea. Rev., 123, 3268-3291.

Brandes, E. A., 1975: Optimizing rainfall estimates with the aid of radar. J. Appl. Meteor., 14, 1339-1345.

Brooks, H. E., C. A. Doswell III, and R. B. Wilhelmson, 1994: The role of midtropospheric winds in the evolution and maintenance of low-level mesocyclones. Mon. Wea. Rev., 122, 126-136.

Chappell, C. F., 1986: Quasi-stationary convective events. Mesoscale Meteorology and Forecasting, P. S. Ray, Ed., Amer. Meteor. Soc., 289-310.

Charba, J. P., 1990: Geographical and seasonal variability in predictability and predictor variables for operational $0-6$ and 3-9 h heavy precipitation forecasts. Preprints, Eighth Conf. on Hydrometeorology, Kananaskis Park, AB, Canada, Amer. Meteor. Soc., 124-131.

Corfidi, S. F., J. H. Merritt, and J. M. Fritsch, 1996: Predicting the movement of mesoscale convective complexes. Wea. Forecasting, 11, 41-46.

Davies, J. M., and R. H. Johns, 1993: Some wind and instability parameters associated with strong and violent tornadoes. 1 . Wind shear and helicity. The Tornado: Its Structure, Dynamics, Hazards, and Prediction, Geophys. Monogr., No. 79, Amer. Geophys. Union, 573-582.

Doswell, C. A., III, 1982: The operational meteorology of convective weather. Vol. I: Operational mesoanalysis. NOAA Tech. Memo. NWS NSSFC-5, 158 pp. [NTIS PB83-162321.]

, 1985: The operational meteorology of convective weather. Vol. II: Storm scale analysis. NOAA Tech. Memo. ERL ESG-15, 240 pp. [NTIS PB85-226959.]

, 1987: The distinction between large-scale and mesoscale contribution to severe convection: A case study example. Wea. Forecasting, 2, 3-16.

— 1991: Comments on "Mesoscale convective patterns of the southern High Plains." Bull. Amer. Meteor. Soc., 72, 389-390.

— , and D. W. Burgess, 1993: Tornadoes and tornadic storms: A review of conceptual models. The Tornado: Its Structure, Dynamics, Hazards, and Prediction, Geophys. Monogr., No. 79, Amer. Geophys. Union, 161-172.

_ , F. Caracena, and M. Magnano, 1985: Temporal evolution of 700-500 mb lapse rates as a forecasting tool-A case study. Preprints, 14th Conf. on Severe Local Storms, Indianapolis, IN, Amer. Meteor. Soc., 398-401.

— M. E. Splitt, and M. Kay, 1992: On storm motion and operational assessment of supercell storm potential using hodographs. Preprints, Fourth AES/CMOS Workshop on Operational Meteorology, Whistler, BC, Canada, Atmos. Environ. Service/Canadian Meteor. and Oceanogr. Soc., 245-252.

Fankhauser, J. C., 1988: Estimates of thunderstorm precipitation efficiency from field measurements in CCOPE. Mon. Wea. Rev., 116, 663-684.

Fritsch, J. M., 1975: Cumulus dynamics: Local compensating subsidence and its implications for cumulus parameterization. Pure Appl. Geophys., 113, 851-867.

— C. F. Chappell, and L. R. Hoxit, 1976: The use of large-scale budgets for convective parameterization. Mon. Wea. Rev., 104, $1408-1418$

, R. J. Kane, and C. R. Chelius, 1986: The contribution of mesoscale convective weather systems to the warm-season precipitation in the United States. J. Climate Appl. Meteor., 25, 13331345.

Hoxit, L. R., and Coauthors, 1978: Meteorological analysis of the Johnstown, Pennsylvania, flash flood, 19-29 July 1977. NOAA Tech. Rep. ERL 401-APCL 43, 71 pp. [NTIS PB-297412.]

Houze, R. A., Jr., S. A. Rutledge, M. I. Biggerstaff, and B. F. Smull, 1989: Interpretation of Doppler weather radar displays of midlatitude mesoscale convective systems. Bull. Amer. Meteor. Soc., 70, 608-619.

Johns, R. H., and C. A. Doswell III, 1992: Severe local storms forecasting. Wea. Forecasting, 7, 588-612. 
Lanicci, J. M., and T. T. Warner, 1991: A synoptic climatology of the elevated mixed-layer inversion over the southern Great Plains in spring. Part II: The life cycle of the lid. Wea. Forecasting, 6, 198-213.

Loehrer, S. M., and R. H. Johnson, 1995: Surface pressure and precipitation life cycle characteristics of PRE-STORM mesoscale convective systems. Mon. Wea. Rev., 123, 600-621.

Maddox, R. A., 1980: Mesoscale convective complexes. Bull. Amer. Meteor. Soc., 61, 1374-1387.

_ 1983: Large-scale meteorological conditions associated with mid-latitude, mesoscale convective complexes. Mon. Wea. Rev., 111, 1475-1493.

_ and C. A. Doswell III, 1982: An examination of jetstream configurations, $500 \mathrm{mb}$ vorticity advection and low-level thermal advection patterns during extended periods of intense convection. Mon. Wea. Rev., 110, 184-197.

—, L. R. Hoxit, C. F. Chappell, and F. Caracena, 1978: Comparison of meteorological aspects of the Big Thompson and Rapid City flash floods. Mon. Wea. Rev., 106, 375-389.

- C. F. Chappell, and L. R. Hoxit, 1979: Synoptic and meso- $\alpha$ aspects of flash flood events. Bull. Amer. Meteor. Soc., 60, 115 123.

Marwitz, J. D., 1972a: The structure and motion of severe hailstorms. Part I: Supercell storms. J. Appl. Meteor., 11, 166-179.

_ 1972b: The structure and motion of severe hailstorms. Part II: Multi-cell storms. J. Appl. Meteor., 11, 180-188.

, 1972c: The structure and motion of severe hailstorms. Part III Severely sheared storms. J. Appl. Meteor., 11, 189-201.

Miller, R. C., 1972: Notes on analysis and severe storm forecasting procedures of the Air Force Global Weather Central. Air Weather Service Tech. Rep. 200 (Rev.), 190 pp. [Available from Air Weather Service, AWS/XTX, Scott Air Force Base, IL 62225-5438.]
Moller, A. R., C. A. Doswell III, and R. Przybylinski, 1990: Highprecipitation supercells: A conceptual model and documentation. Preprints, 16th Conf. on Severe Local Storms, Kananaskis Park, AB, Canada, Amer. Meteor. Soc., 52-57.

Moore, J. T., S. M. Nolan, F. H. Glass, D. L. Ferry, and S. M. Rochette, 1995: Flash flood-producing high-precipitation supercells in Missouri. Preprints, 14th Conf. on Weather Analysis and Forecasting, Dallas, TX, Amer. Meteor. Soc., (J4)7-12.

Mostek, A., and N. W. Junker, 1989: Quantitative precipitation forecast verification at the National Meteorological Center. Preprints, 12th Conf. on Weather Analysis and Forecasting, Monterey, CA, Amer. Meteor. Soc., 633-637.

National Weather Service Western Region Headquarters, 1982: Report on the Moapa Valley flash flood. Report of the Survey Team, 23 pp. [Available from National Weather Service Western Region Headquarters, Salt Lake City, UT 84138.]

NOAA, 1991: National implementation plan for the modernization and restructuring of the National Weather Service. Fiscal Year 1991 Annual Update, 132 pp. [Available from National Weather Service Headquarters, Silver Spring, MD 20910.]

Olson, D. A., N. W. Junker, and B. Korty, 1995: Evaluation of 33 years of quantitative precipitation forecasting at the NMC. Wea. Forecasting, 10, 498-511.

Rotunno, R., 1993: Supercell thunderstorm modeling and theory. The Tornado: Its Structure, Dynamics, Hazards, and Prediction, Geophys. Monogr., No. 79, Amer. Geophys. Union, 57-73.

Smull, B. F., and M. L. Weisman, 1993: Comparison of the observed and simulated structure of a bow-shaped mesoscale convective system. Preprints, 17th Conf. on Severe Local Storms, St. Louis, MO, Amer. Meteor. Soc., 557-561.

Spiegler, D. B., 1970: Snow prediction-A formidable challenge. Weatherwise, 23, 212-220.

Weisman, M. L., 1993: The genesis of severe, long-lived bow echoes. J. Atmos. Sci., 50, 645-670. 